\title{
Evaluating sulfur-free lignin as a sustainable additive for soil improvement against frost resistance
}

\author{
Liu, Yaowu; Zheng, Wenle; Wang, Qing; Cao, Chengjun; Chang, Mushi; Rocchi, Irene
}

Published in:

Journal of cleaner production

Link to article, DOI:

10.1016/j.jclepro.2019.119504

Publication date:

2020

Document Version

Peer reviewed version

Link back to DTU Orbit

Citation (APA):

Liu, Y., Zheng, W., Wang, Q., Cao, C., Chang, M., \& Rocchi, I. (2020). Evaluating sulfur-free lignin as a sustainable additive for soil improvement against frost resistance. Journal of cleaner production, 251, [119504]. https://doi.org/10.1016/j.jclepro.2019.119504

\section{General rights}

Copyright and moral rights for the publications made accessible in the public portal are retained by the authors and/or other copyright owners and it is a condition of accessing publications that users recognise and abide by the legal requirements associated with these rights.

- Users may download and print one copy of any publication from the public portal for the purpose of private study or research.

- You may not further distribute the material or use it for any profit-making activity or commercial gain

- You may freely distribute the URL identifying the publication in the public portal 

soil improvement in geotechnical engineering with focus on frost

\section{resistance}

4 Yaowu Liu ${ }^{a}$, Wenle Zheng ${ }^{a}$, Qing Wang ${ }^{a^{*}}$, Chengjun Cao ${ }^{a}$, Mushi Chang ${ }^{a}$, Irene Rocchi ${ }^{b}$

5 a. College of Construction Engineering, Jilin University, Changchun 130026, China

b. Department of Civil Engineering, Technical University of Denmark, Brovej, Building 119, 2800 Kgs, Lyngby, Denmark

Abstract:

This study investigates using Sulfur-Free Lignin (SFL) as a stabilizer to improve and reinforce soil for civil engineering construction. To comprehensively evaluate the engineering performance of SFL stabilized soil, 3, 7, 10, 12 and 15\% mixtures were used and the influence of climate factors (assessed subjecting the soil to different freeze-thaw cycles) was also considered. The experimental program investigated mechanical strength (unconfined compressive strength) and physicochemical properties, which included grain size distribution, Atterberg limits, variation of elemental and mineral composition, $\mathrm{pH}$, cation exchange capacity, X-ray diffraction/ fluorescence and thermal conductivity. In addition, micro-characterization through SEM and pore size distribution was also covered. A considerable improvement of the mechanical properties was observed, which increases with SFL content up to $12 \%$. This was based on changes in the physical and not chemical properties, hinting that the stabilization mechanism consists in physical binding unlike for traditional soil stabilizers. Moreover, it was found that SFL addition improved frost resistance. Based on these results, utilizing SFL as a soil stabilizer for application in earthworks shows great potential and would promote the bioethanol industry and engineering construction to be more sustainable and greener, particularly because it does not risk inducing soil $\mathrm{pH}$ contamination unlike traditional chemical agents. 
Keywords: sulfur-free lignin, soil improvement, freeze-thaw cycles, sustainable geotechnical engineering, bioethanol waste elimination

\section{Introduction}

Ensuring the safety and reliability of earth structure such as foundations, embankment dams, canals and rail/road subgrade is one of the main concerns of geotechnical engineering (Jalili et al., 2018). Sometimes foundation soils display undesirable engineering properties and therefore stabilization may be required, e.g. by compaction or preloading, dewatering, electroosmosis or addition of cementing agents, where the last are typically most convenient from the perspective of economic requirements and general applicability. However, traditional cementing agents such as lime, Portland cement or fly ash, have considerable drawbacks: (i) Clinker production for these traditional agents emits large $\mathrm{CO}_{2}$ amounts and consumes huge energy. For example, typical manufacturing of $1 \mathrm{t}$ Portland cement consumes $5000 \mathrm{MJ}$ and releases about $0.95 \mathrm{t} \mathrm{CO}_{2}$, contributing to about $4-5 \%$ of global $\mathrm{CO}_{2}$ emissions from fuel consumption and industrial activities (Xi et al., 2016; Shibab et al, 2018). (ii) The $\mathrm{pH}$ values of traditional treated soils have clear increasing trends, which lead to an alkaline environment posing a threat to the crop yield capacity and the quality of groundwater (Sreekrishnavilasam et al., 2007). (iii) Due to the excessively brittle performance, these treated soils may have an adverse effect on the stability of structures, especially under dynamic cyclic loads. Obviously, these problems cause a huge environmental burden and are incompatible with the global concept of sustainable development (Jefferis, 2008; Reddy and Kumar, 2019). Therefore, it is necessary to find innovative soil stabilizers, which are environment-friendly and energyefficient, to enhance the geotechnical properties of problematic soils.

Lignin is the second most abundant biopolymer in the world after cellulose (Pérez et al., 2019). In nature, lignin polymer usually fills the space in the cell wall between cellulose, and hemicellulose, it forms xylem cells and lignifies sclerenchyma fibers, becoming the crucial structural part of the lignocellulose polymer (Martone et al., 2009). Until recently, lignin was mainly generated as a by-product from paper and timber industry. Today lignin is also a byproduct or waste material of maize plant based ethanol production. Fig.1 shows the industrial 
process of the maize plant ethanol production. Firstly, corn is peeled off as food, then the remaining corncob and maize straw are used as feedstock, which is converted to bioethanol through an environmental-friendly process of biological pretreatment and enzymatic degradation. The solid residue can be further processed to obtain multiple co-products including cellulose, hemicellulose and lignin. Cellulose is an important raw material for producing bioethanol. Hemicellulose, which is rich in five-carbon sugars xylose and arabinose and the six-carbon sugars mannose, can be used to produce xylitol gum, probiotics yoghurt or other high value products. However, lignin is predominantly used and investigated as a fuel (Hamelinck et al., 2005; Li et al., 2015), as it requires depolymerisation for other uses (Chio et al., 2019). For the biofuel industry to become truly sustainable, it is necessary to convert lignin into a high-value product (Bothast and Schlicher, 2005).

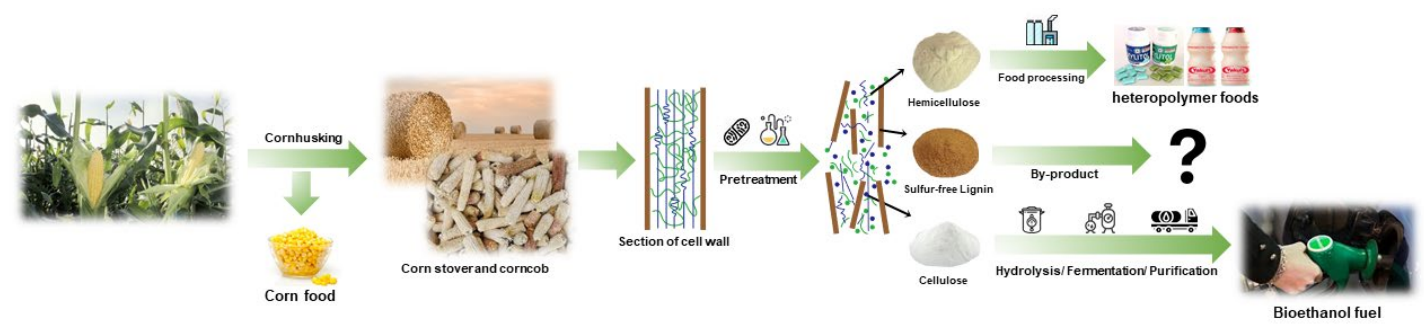

Fig.1. Industrial process of maize plant ethanol production

In the recent past, many studies have been implemented to assess the feasibility of utilizing lignin in the construction industry and in particular as an in innovative agent to stabilize geomaterials. For example, lignin is being increasingly used as a reinforcement in composites due to its good thermal insulation properties (Alsina et al., 2005; Nechita and Ionescu, 2018). Furthermore, Peralta et al. (2012) suggested its use in the pavement industry as an asphalt modifier or substitute.

Surdahl et al. (2007) evaluated lignin as a stabilizer for silt roadways through a field test in south central Arizona and found it to be among the best performers in a group of six additives. Santoni et al. (2002) and Tingle and Santoni (2003) used lignin to treat silty and clayey soils, respectively, and found it to be more effective than traditional stabilizers in waterproofing, although unconfined compressive strength was better than traditional stabilizers for fine grained soils only. Similar conclusions regarding water resistance were reported by Ta'negonbadi and Noorzad (2017). Vinod et al. (2010) conducted experiments to assess the internal erosion 
behavior of lignin-treated dispersive and erodible soils using a process simulation apparatus for internal crack erosion and found the erosion resistance of treated soil to have significantly improved. They also investigated and identified the mechanisms by which a remoulded expansive soil was modified by lignin (Alazigha et al., 2018). More recently, Zhang et al. (2017, 2018b) performed a series of laboratory and field tests to present a comprehensive investigation on engineering properties of lignin-stabilized silty soils and successfully employed nondestructive techniques (i.e. shear-wave velocity and thermal resistivity) to trace the evolution of strength for the lignin-stabilized soils.

This research demonstrates that lignin could indeed improve the geotechnical performance of soils increasing their mechanical strength and improving resistance to erosion and soil expansion. However, all of the mentioned studies investigated sulfite lignin (lignosulfonates) derived from paper industry, while the lignin obtained from ethanol production is sulfur free instead, which results in different properties. In particular, this contains more lignin (about 50$75 \%)$ with moderate macromolecular size and its structure is similar to that of native lignin. Limited studies have been carried out to examine the behavior of bioethanol-derived sulfur-free lignin to improve soils properties for civil engineering applications (e.g. Ceylan et al., 2012). As many engineering applications such as roads, railroads and pipelines are built in seasonally frozen regions, there is also a need to evaluate the performance of SFL stabilized soil under freeze-thaw conditions. Research has shown that freeze-thaw cycles severely affect the engineering properties of soils resulting in a clear decrease in soil stability (Simonsen and Isacsson, 2001; El-Maaty, 2016). In particular, Khoury and Zaman (2007) have reported that the durability of stabilized soils under repeated freeze-thaw action varies, depending on the type and proportion of stabilizer used.

As stated above, this study investigates the potential to use Sulfur-Free Lignin (SFL) based on a bioethanol industry by-product as a geotechnical stabilizer and highlights the performance of the stabilized soils considering climatic factors (with a high number of Freeze-Thaw cycles (F-T)). The physicochemical properties of the SFL stabilized soil under different F-T cycles were investigated, including Atterberg limits, Grain Size Distribution (GSD), Cation Exchange Capacity (CEC), $\mathrm{pH}$ and thermal conductivity. The elemental composition and crystal structure before and after freeze-thaw cycles were tested by X-ray Diffraction (XRD) and X-ray 
Fluorescence (XRF). In addition, mechanical characterization was also performed by

110 Unconfined Compressive Strength (UCS). Finally, the influence of F-T cycles on the stabilized

111 soil at the microscopic level was confirmed by Mercury Intrusion Porosimertry (MIP) and

112 Scanning Electron Microscopy (SEM).

\section{Material tested}

\subsection{Soil}

The soil tested was sampled approximately $40 \mathrm{~cm}$ underground from Qian'an in western

116 Jilin Province, China. The site is located in Song-Nen Plain, one of the three largest soda salinealkali soil areas (Wang, 1993). The physicochemical properties of the soil, including natural

118 density and water content, Atterberg limits, optimum water content and maximum dry unit

119 weight, total dissolved solids, organic matter content and $\mathrm{pH}$ are presented in Table 1 . The particle-size distribution of the tested soil, measured by Laser Diffraction Particle Analyser

121 (LDPA), is shown in Fig.3. It contains $18.5 \%$ sand $(2-0.075 \mathrm{~mm}), 52.4 \% \operatorname{silt}(0.075-0.005 \mathrm{~mm})$ and $29.1 \%$ clay $(<0.005 \mathrm{~mm})$. According to the engineering classification standards (Chinese standard, 1999), the tested soil can be classified as a silty clay. Fig.4 shows the mineral composition of the soil used in this study as obtained from XRD analysis. This consists mostly of Quartz, Clay minerals, Plagioclase and Calcite.

126

\section{Table 1}

\section{Basic properties of nature soil}

\begin{tabular}{lr}
\hline Property & Characteristic \\
\hline Soil natural density $\left(\mathrm{g} / \mathrm{cm}^{3}\right)$ & 1.909 \\
Natural water content $w(\%)$ & 21.58 \\
liquid limit $(\%)$ & 34.85 \\
plasticity limit $(\%)$ & 18.47 \\
plasticity index $(\%)$ & 16.49 \\
Optimum moisture content $(\%)$ & 15.6 \\
Maximum dry unit weight $\left(\gamma_{\mathrm{dmax}}\right),\left(\mathrm{Kg} / \mathrm{m}^{3}\right)$ & 1.781 \\
Total dissolved solids $(\mathrm{mmol} / \mathrm{kg})$ & 43.92 \\
Organic matter content $(\%)$ & 0.40 \\
$\mathrm{pH}$ & 8.7 \\
\hline
\end{tabular}




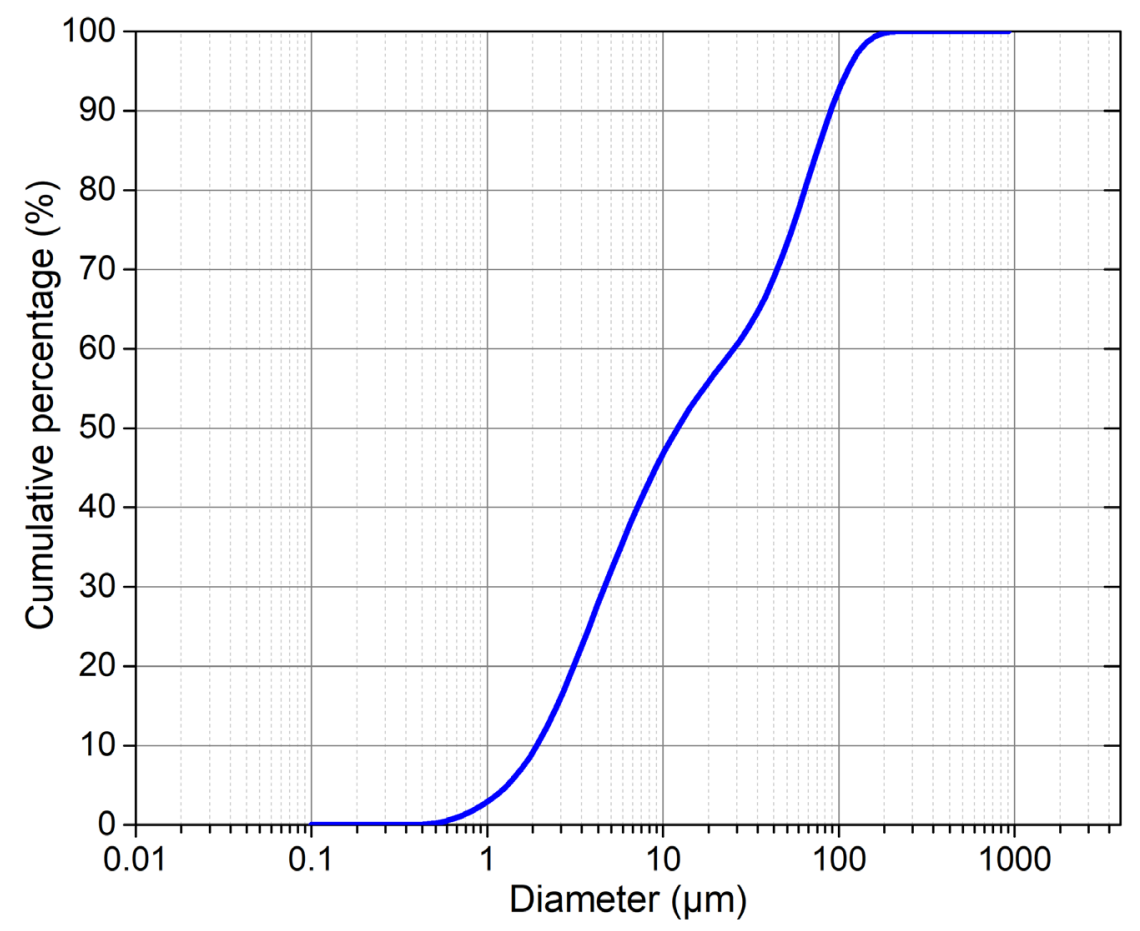

Fig. 3. Grain size distribution of natural soil.
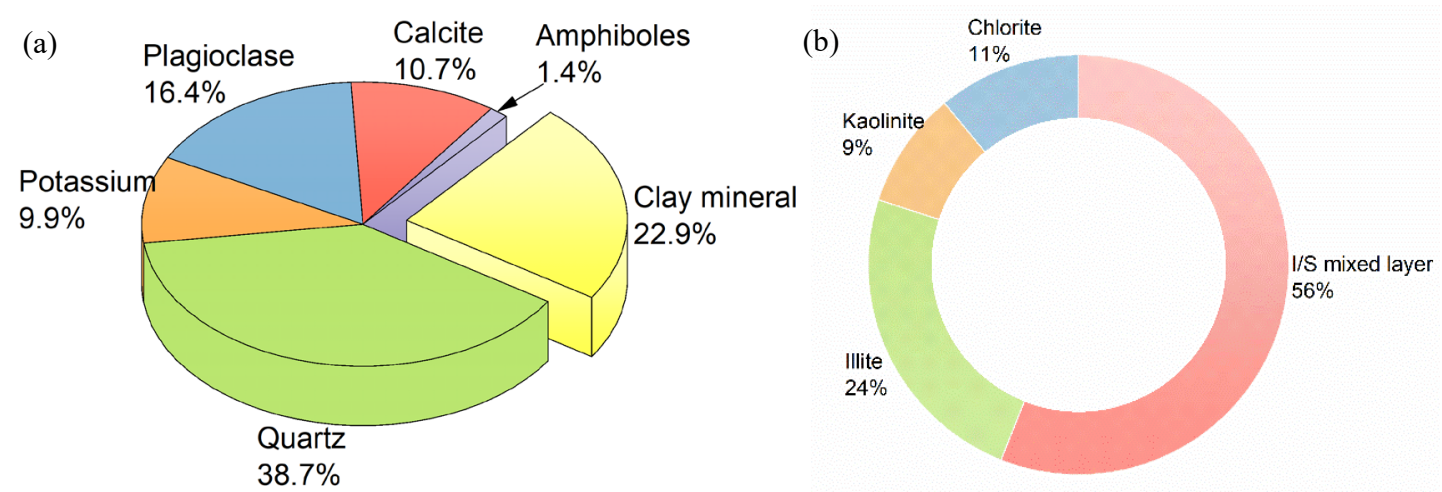

Fig. 4. Mineral composition of natural soil. (a) bulk sample and (b) clay fraction

\subsection{Lignin}

The Sulfur-Free Lignin (SLF) used is a recycled by-product from corn-based ethanol

133 industry. Sulfur-free lignin form bio-ethanol industries is nontoxic, environmentally friendly

134 and sustainable. This kind of lignin is a light-brown powder with a fragrance odour that is

135 slightly soluble. According to the producer, it contains $91.2 \%$ lignin, $0.12 \%$ residual

136 cellulose/hemicellulose, and $0.67 \%$ ash content. The infrared spectrum of sulfur-free lignin are 
presented in Fig.5 as recorded by the Thermo Scientific Nicolet iS10 Fourier transform infrared spectrometer. It can be observed that different strong band identifications include hydroxyl group $\left(3420 \mathrm{~cm}^{-1}\right), \mathrm{CH}$ stretching vibrations $\left(2937,2850 \mathrm{~cm}^{-1}\right), \mathrm{C}=\mathrm{O}$ group $\left(1703\right.$ and $1602 \mathrm{~cm}^{-}$ ${ }^{1}$, respectively), aromatic ring and C-H deformation (1513 and 1463, $1032 \mathrm{~cm}^{-1}$, respectively), and C-O stretching for methoxyl groups $\left(1221 \mathrm{~cm}^{-1}\right)$. According to previous studies (Abe et al., 2010; Lin and Dence, 2012), lignin polymer is widely accepted to contain three major precursors: (1) coniferyl alcohol, (2) sinapyl alcohol and (3) p-coumaryl alcohol as shown in Fig. 5.

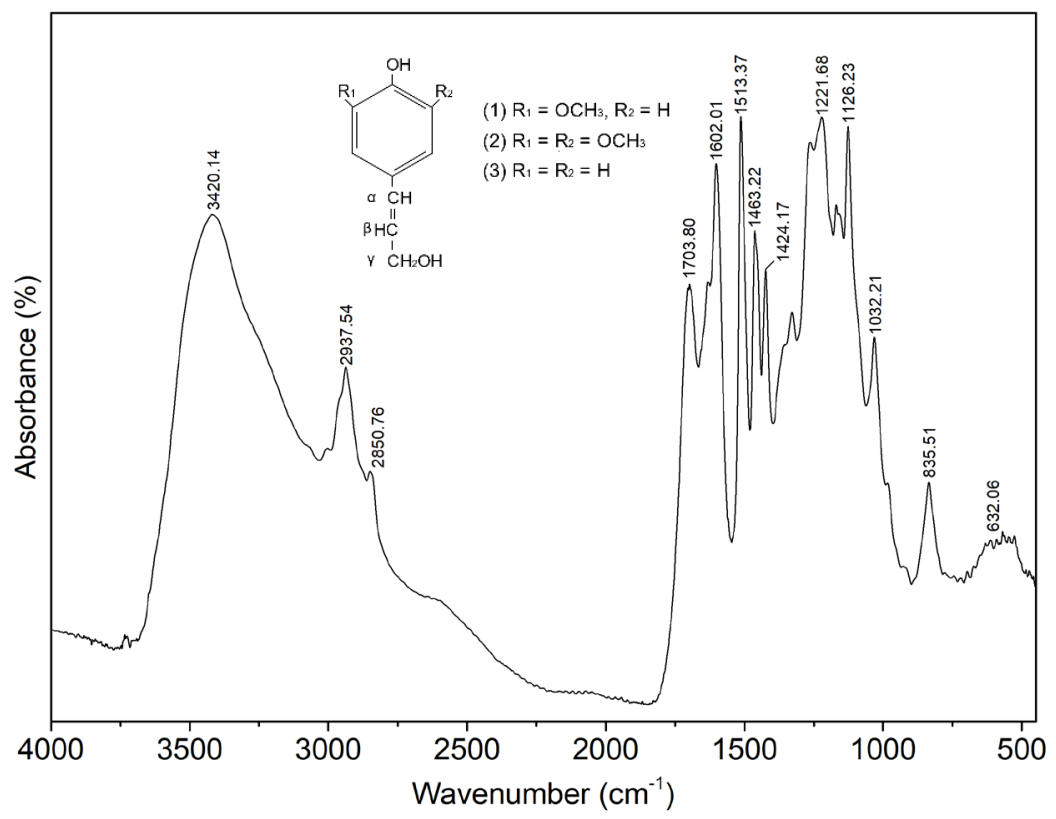

Fig. 5. FTIR spectrum of the sulfur-free lignin and three basic-units in lignin molecule (Lin and Dence, 2012).

\section{Experimental procedure}

\subsection{Sample preparation}

149 a particle size that could pass through a $2 \mathrm{~mm}$ sieve to remove any oversized particles for

150 experiments. Subsequently, the SLF was added to the soil in amounts calculated on the basis of 151 the soil dry mass and the designed additive contents $(0,3,10,12,15 \%)$. To distribute the 
additive uniformly, the mixture of SFL and soil was thoroughly mixed for about 5 minutes in a dry state. Afterwards, a predetermined weight of distilled water was added into the mixture. This was also hand-mixed for 5 minutes and then placed in a sealed metal bucket for $24 \mathrm{~h}$ to achieve a homogeneous moisture distribution. Note that the moisture content of all samples was the same as the optimum moisture content of the natural soil. Finally, the mixture was put into a hollow steel mold, having a $39.1 \mathrm{~mm}$ inner diameter and $80.0 \mathrm{~mm}$ height and compacted to $95 \%$ of the maximum dry density of the natural soil by using a hydraulic frame. Right after, the soil specimens were immediately sealed with a waterproof membrane and cured at $20 \pm 2^{\circ} \mathrm{C}$ and relative humidity $92 \pm 3 \%$ in a standard curing room for 28 days.

\subsection{Testing methods}

A series of experimental tests were performed including physical/chemical, mechanical and micro-characterization to investigate the changes in geotechnical properties of sulfur-free lignin stabilized soil undergoing a high number of Freeze-Thaw (F-T) cycle. The related damage mechanisms were then identified. The experimental program included Atterberg limits, Grain Size Distribution (GSD), Thermal Conductivity (TC), Cation Exchange Capacity (CEC), pH, X-ray Diffraction (XRD), X-ray Fluorescence (XRF), Unconfined Compressive Strength (UCS), Mercury Intrusion Porosimerty (MIP) and Scanning Electron Microscopy (SEM). The experimental devices, techniques, and methodology adopted in this study are briefly described in the following paragraphs. Fig. 2 illustrates a schematic overview of the testing program.

\subsubsection{Freeze-thaw cycles}

The sealed specimens underwent cyclic F-T cycles after 28 days curing in an automatic closed system, where no moisture was supplied or allowed to escape during the freeze-thaw process. The F-T cycles imposed cover a large range of values starting from the initial state (no cycle) and progressively 10, 30, 60, 120 cycles. In a single F-T cycle, the specimen was exposed to freezing condition at a temperature of $-20^{\circ} \mathrm{C}$ for $12 \mathrm{~h}$ and then it was allowed to thaw at a room temperature of about $20^{\circ} \mathrm{C}$ for $12 \mathrm{~h}$ to ensure complete frost penetration and ice-melting, respectively. When the designed number of F-T cycles was achieved, the other tests were performed on this set of specimens. 


\subsubsection{Physicochemical tests}

181 The Atterberg limits of all sulfur-free lignin stabilized soil specimens were measured and 182 calculated in accordance with ASTM D4318-10 (ASTM, 2010). The grains size distribution 183 was determined using a Laser Diffraction Particle Analyser (Bettersize BT-9300 LD) as 184 described by Yang and Wei (2012). A DRE-2C thermal conductivity analyzer was used to 185 measure the thermal properties of all specimens after targeted F-T cycles. This device utilizes 186 transient plane source method with an accuracy of $0.1 \mathrm{~W} /(\mathrm{m} \cdot \mathrm{K})$. Since the test temperature 187 has an effect on the measured thermal conductivity, this was set to $15 \pm 0.5^{\circ} \mathrm{C}$ for all 188 specimens (Cheng et al., 2014). The ferric ammonium EDTA method was used to determine 189 the Cation Exchange Capacity in accordance to the Chinese Standard (1999). The specimen $\mathrm{pH}$ 190 was obtained by using a PB-10 probe (Sartorius Crop. Germany) as per ASTM D4972 (ASTM, 191 2007).

\section{$192 \quad$ 3.2.3 Mechanical tests}

193 The unconfined compressive test, which is an effective method for strength evaluation, 194 was carried out as per ASTM D4219 (ASTM, 2002) on cylindrical specimens having $39.1 \mathrm{~mm}$ 195 diameter and $80 \mathrm{~mm}$ height. The ASTM standard recommends applying the axial load to 196 produce axial strain at rate of approximately $1.0 \mathrm{~mm} / \mathrm{min}$ for ductile materials and $0.3 \mathrm{~mm} / \mathrm{min}$ 197 for brittle materials. In order to test all mixtures under similar conditions, as well as to isolate 198 the effect of strain rate on strength behavior, a constant displacement rate of $1.0 \mathrm{~mm} / \mathrm{min}$ was 199 applied in a YSH-2 Soil Unconfining Pressure Test Apparatus (Nanjing Soil Instrument, China).

200 The unconfined compressive strength was defined as the peak value in the stress-strain curve 201 as shown in Fig. x. Since the height-diameter ratio $(H / D)$ of a specimen has an effect on the 202 compressive strength (Lamond and Pielert, 2006), it should be noted that the ratio used was 2032.05. 


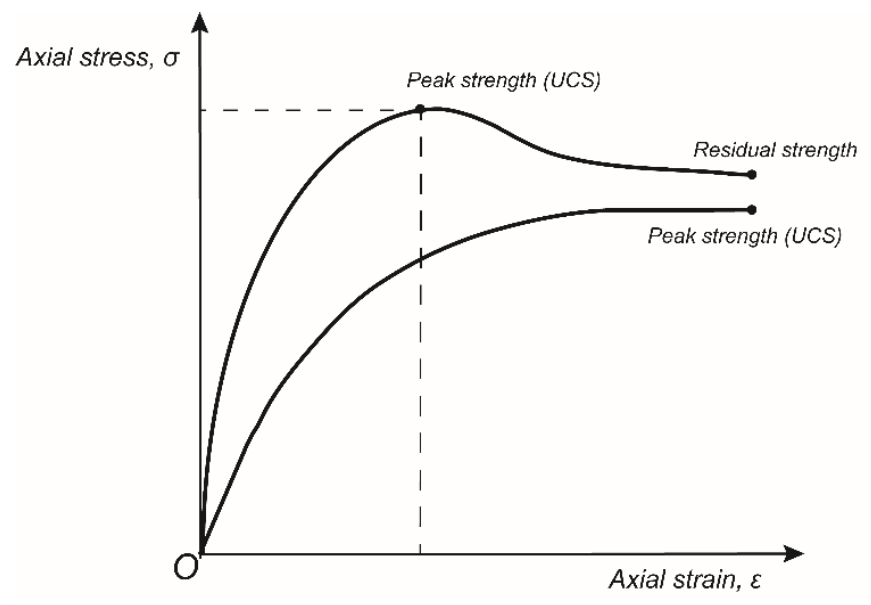

Fig. x. Using peak strength of stress-strain curve as unconfined compressive strength.

\subsubsection{Elemental and mineral composition tests}

The crystallographic structure of the stabilized soil was investigated using an X-ray diffractometer (D/MAX-2500, Rigaku, Japan) with a $\mathrm{Cu}-\mathrm{K} \alpha$ radiation source at a voltage of 30 $\mathrm{KV}$. The scanning speed was $6^{\circ}(2 \theta) /$ min over an angle range of $2.6^{\circ}$ to $45^{\circ}$. The "K-value" method was used for XRD quantitative analysis in accordance to SY/T 5163-2010 Standard (Chinese Standard, 2010a). X-ray fluorescence tests were also carried out to determine the

211 elemental composition of the specimen. The tube-above wavelength dispersive X-ray fluorescence spectrometer (ZSX Primus II, Rigaku, Japan) was used as per GB/T 14506 Standard (Chinese Standard, 2010b). The quantitative data analysis was performed with the bundled EZ-scan software.

\subsubsection{Micro-characterization tests}

The pore size characteristics of the treated soil were analysed using the Mercury Intrusion Porosimetry (MIP) technique. In this technique, mercury intrudes the voids of the porous medium only if sufficient pressure is applied. The intrusion pressure is then converted to the pore diameter according to Laplaces's capillarity law also known as Washbur's equation (Washburn, 1921). Cubic specimens (about $10 \mathrm{~mm}$ length), which were sub-sampled from each compacted specimen, were freeze-dried immediately before MIP testing as suggested by Delage (1984) to avoid fabric alteration. The MIP device used was the AUTO-PORE 9500 (Micromeritics Instrument Corp. America) with a maximum intrusion pressure of $228 \mathrm{MPa}$. Scanning Electron Microscopy (SEM) was also conducted to more directly observe the spatial configuration (i.e. sizes, shapes and associated pores) of sulfur-free lignin stabilized soil 
226 particels. The technique provides qualitative information that can be interpreted along with MIP

227 test results. The SEM specimens were also pretreated following the same procedures as for MIP.

228 In addition, the specimens were sputter-coated with a thin gold layer before SEM testing. The

229 images were taken with a Phenom ProX Desktop scanning electron microscope (Thermo Fisher

230 Scientific, America).

231 


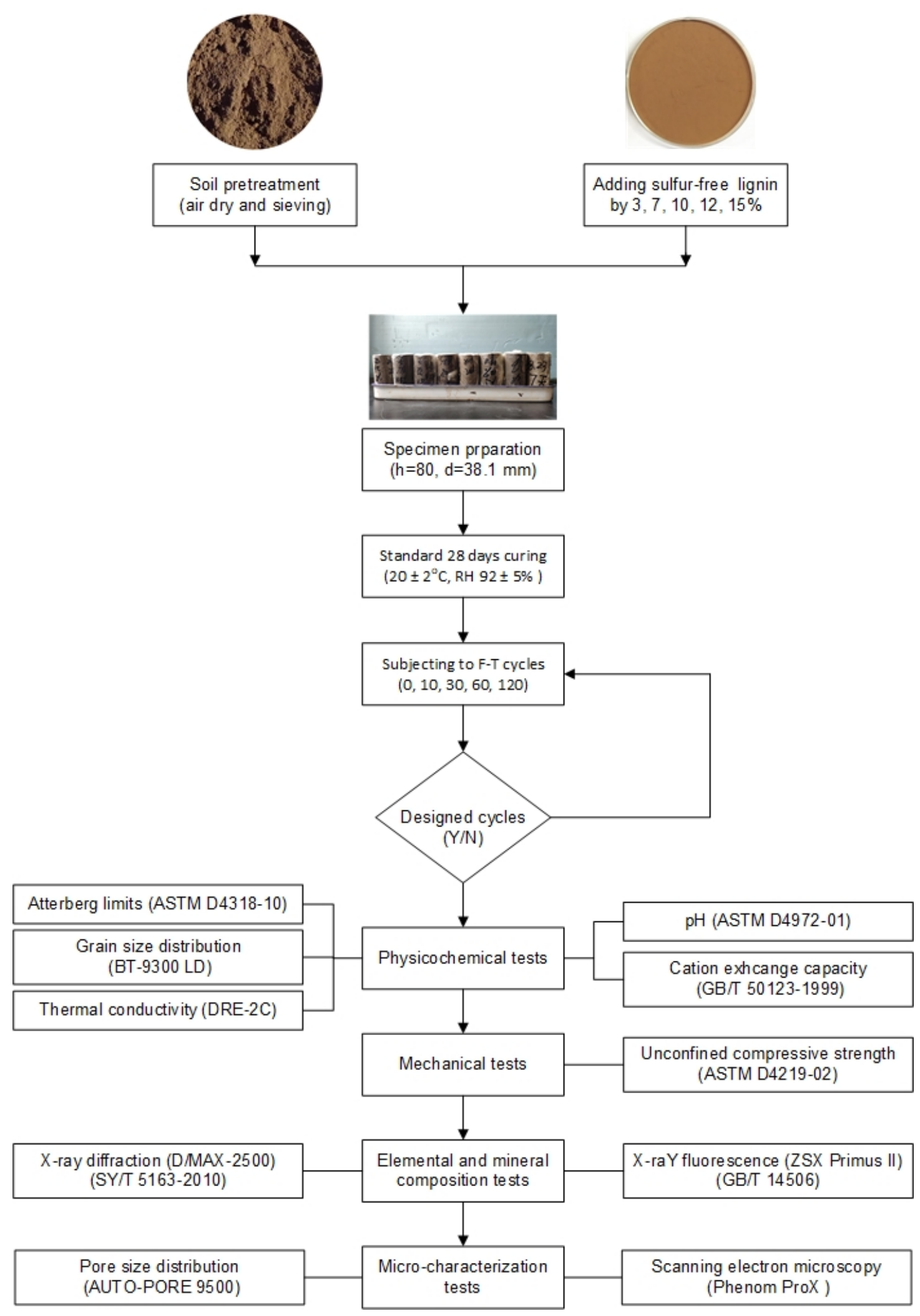

Fig. 2. Schematic overview of the work performed in this study. 


\subsection{Physicochemical tests}

\subsubsection{Atterberg limits}

The liquid limit $\left(w_{L}\right)$ defines the water content where the soil behavior transitions from a plastic state to that of a viscous liquid, while the plastic limit $\left(w_{P}\right)$ defines the water content where a soil transitions from a semi-solid to a plastic state. These water contents define the limits within which the soil is workable and are termed after Atterberg who first defined them. Fig.6 shows the influence of SFL content and F-T cycles on liquid limit $\left(w_{L}\right)$, plastic limit $\left(w_{P}\right)$ and plastic index $\left(I_{P}=w_{L}-w_{P}\right)$. It can be observed in Fig. 6 (a) that $w_{L}$ and $w_{P}$ increase approximately $18 \%$ and $14 \%$ respectively when the SFL content changes from $0 \%$ to $15 \%$, resulting in a considerable increase in $I_{P}$ of $24 \%$. These results are consistent with those on silt soils stabilized with lignosulfonate presented by Zhang et al. (2018c). The increase in $w_{L}$ and $w_{P}$ is thought to be due to soil particles being bonded by the lignin fibers, resulting in a more stable soil structure. Consequently, more water is required to complete state transitions. The low solubility of SFL, which leads to strong-holding capacity in the stabilized soil, may also explain these results. The results are consistent with those on silt soils stabilized with lignosulfonate presented by Zhang et al. (2018c).

With respect to the F-T cycles effects on $I_{P}$ there is no clear trend, as shown in Fig. 6(b),

251 implying that F-T cycles have little influence on Atterberg limits. This result is also consistent 252 with former studies (Eigernbrod 1996, Liu et al., 2019). Dagesse (2015) saw no effect of 253 freezing and thawing on soil plasticity based on indoor experimental data, but he pointed out 254 that the small samples used to measure liquid and plastic limits would reflect small scale changes and this might have a significant effect during project designing. 
(a)

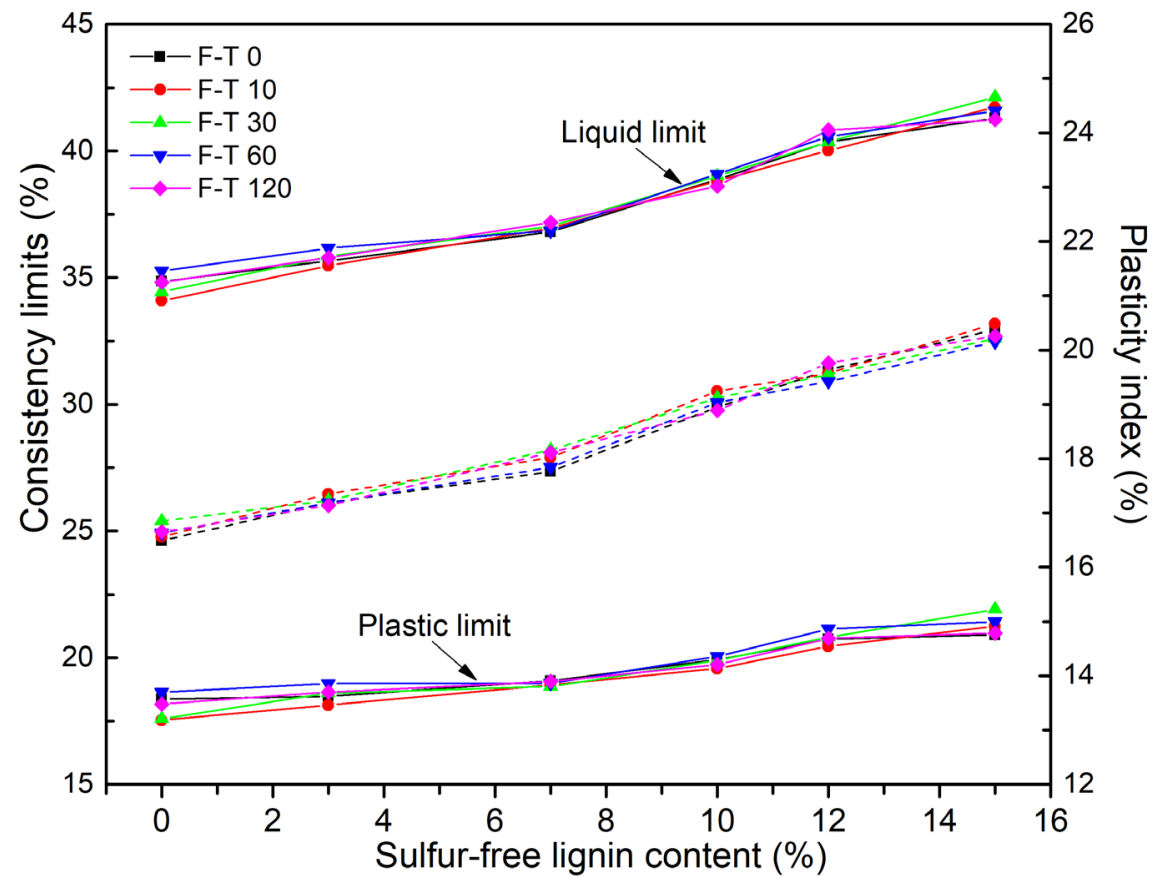

(b)

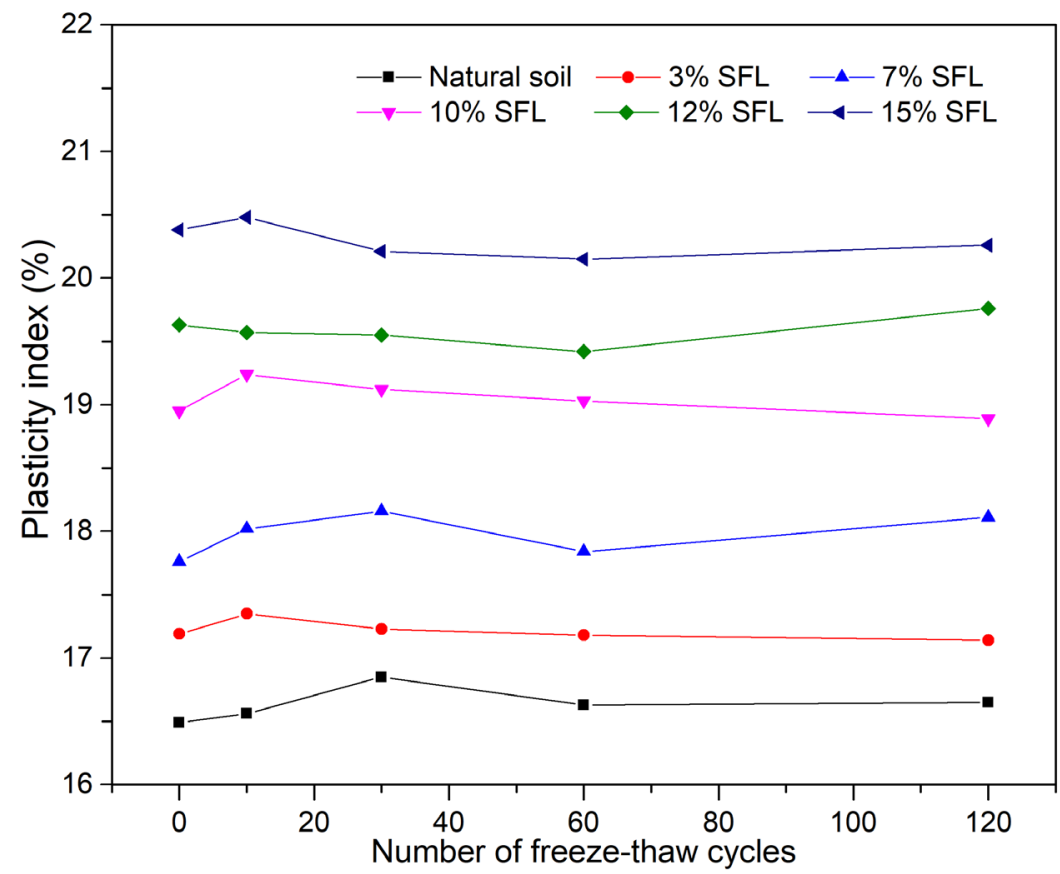

Fig. 6. Variations of Atterberg limits of different sulfur-free lignin content with different F-T cycles.

\subsubsection{Grain size distribution}

Fig.7 displays the variation in grain size distribution of the stabilized soil for different SFL contents that underwent different F-T cycles. The sand percentage of the stabilized soil has an

260 increasing trend with addition of SFL up to $7 \%$, and then starts to decrease. The amount follows 
261 an opposite trend than for the silt group, where a smaller percentage was apparent in the $7 \%$

262 SFL stabilized soils. However, the percentage of clay keeps on decreasing as the SLF content

263 increase. In order to better analyse the causes of grain size changes, the pure SFL powder was

264 also tested using the same method. This contains $15 \%$ clay-size particles $(<0.005 \mu \mathrm{m}), 79 \%$

265 silt particles $(0.005-0.075 \mu \mathrm{m})$ and about $6 \%$ sand-size particles $(>0.075 \mu \mathrm{m})$. These

266 results indicate that SFL could convert significantly fine particles into coarse particles by

267 aggregating or cementing them up to 7\% SFL content, afterwards, the relative amount of the

268 coarse particles gradually decreases because SFL contains almost $80 \%$ particles belonging to

269 the silt group. However, this does not necessarily mean that the cementing process stops or 270 weakens.

271 In Fig. 7, it is also seen that the F-T cycles have a significant effect. The sand percentage 272 of all specimens shows a decreasing trend in Fig. 7(a). The sand percentage of the untreated 273 soil and the low content SFL stabilized soil rapidly decreases by approximately $5 \%$ during the 274 first 60 cycles, while the high SFL content stabilized soil has a slight decrease throughout the 275 F-T process. The silt percentage also shows a decrease except for the natural soil and the 3\% 276 SFL stabilized soil. Consequently, the clay percentage increases with the F-T cycles, and 277 similarly the most changes are found in natural and low dosage specimens in Fig.7 (c). 

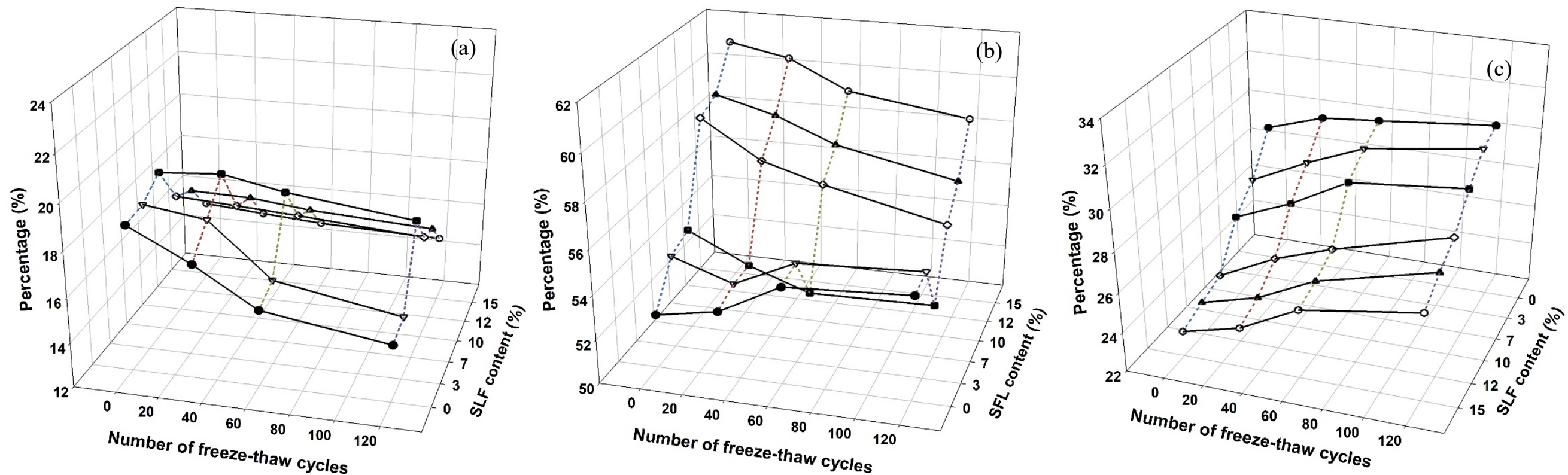

Fig. 7. Relationship between Sulfur-free lignin content and grain size composition of stabilized soil under different F-T cycles: (a) sand group (2-0.075 mm); (b) silt group (0.075-0.005 mm); (c) clay group (<0.0 $05 \mathrm{~mm}$ ). 
According to the test results described, the redistribution of soil particles size indicates that

281 SFL plays a role in bonding soil particles, while F-T cycles have opposite effects, breaking up 282 coarse particles to enrich the fine group. However, the SFL stabilized soil undergoes less 283 changes during F-T cycles, which agrees with studies by Russo et al. (2007) who also conducted 284 F-T cycles on different soils. In addition, the results confirm intense fragmentation of particles 285 at the beginning of the F-T cycling process and gradual decrease subsequently, as already 286 observed by Zhang et al. (2016). Numerous studies have been examined the effects of F-T 287 cycles on grain size distribution of soil. According to Konichev (1981), sand particles are 288 fragmented as a result of the freezing thawing process and the grading tends towards a certain 289 particle size and degree of the fragmentation in relation to its initial particle size distribution. 290 Furthermore, according to Bullock et al. (1988), the F-T cycles destroy bonds that hold 291 aggregates together, leading to a variation in soil particle size distribution.

\subsection{3 pH \& CEC}

Fig. 8 reports the $\mathrm{pH}$ variations for different SFL stabilized soils that underwent 30 and 120

294 F-T cycles. The $\mathrm{pH}$ of the SFL stabilized soil has a slight decrease with SFL content but remains 295 comparable with the natural soil, meaning SFL does not change significantly the $\mathrm{pH}$ of soils. 296 This result is different from previous studies that report strongly alkaline $\mathrm{pH}$ after treatment 297 with lignosulfonate obtained from paper industry (Lisperguer et al., 2009; Zhang, 2015), cement 298 (Chew et al., 2004) or lime (Sharma et al., 2012). Compared with traditional chemical stabilizer 299 (i.e. lime, cement, fly ash) and lignosulfonate, this is a clear advantage of SFL. It also can be 300 seen from Fig. 8 that the F-T cycles have no significant influence on $\mathrm{pH}$ for all soil specimens, 301 due to testing in a closed environment.

302 Fig.9 shows an increase in CEC, as more SFL is added. Using the $10 \%$ and $15 \% \mathrm{SFL}$ 303 stabilized soil as an example, the CEC grows by 6.7 and $18.1 \mathrm{mmol} / 100 \mathrm{~g}$ in the condition of 304 no F-T cycles. This is attributed to SFL being separated from cellulosic feedstock (corncobs and corn stover) using steam explosion followed by alkaline $(\mathrm{NaOH})$ addition during the 306 pretreatment of bioethanol production, after which acid is added to neutralize the $\mathrm{pH}$ values. However the $\mathrm{Na}^{+}$, which possesses a strongly exchangeable ability, remains in SFL causing an 
308 三 increase in CEC. According to Tang (1998), high CEC causes the loosely bound water layer on 309 the clay particles to become thicker, resulting in soil instability. Frenkel et al. (1978) reported 310 that the increasing exchangeable sodium percentage enhances soil dispersion, especially the 311 maximum dispersion occurred at $\mathrm{pH}$ 8.3. Thus, SFL should be used with more caution when 312 treating dispersive soils or mixing with other materials in engineering applications. Furthermore, 313 there are no marked changes in CEC for all specimens before and after F-T cycles similarly to 314 the $\mathrm{pH}$ tests.

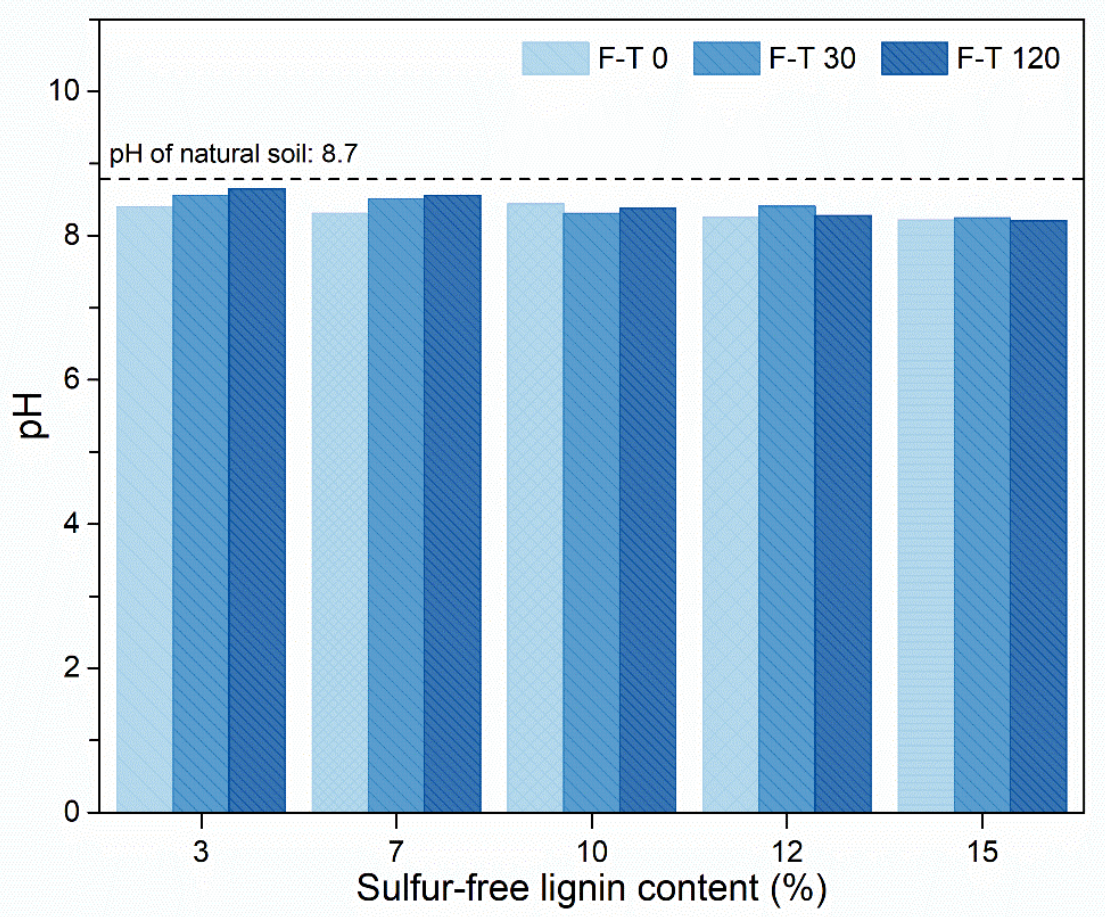

Fig. 8. Variations of $\mathrm{pH}$ for different sulfur-free lignin content with different F-T cycles. 


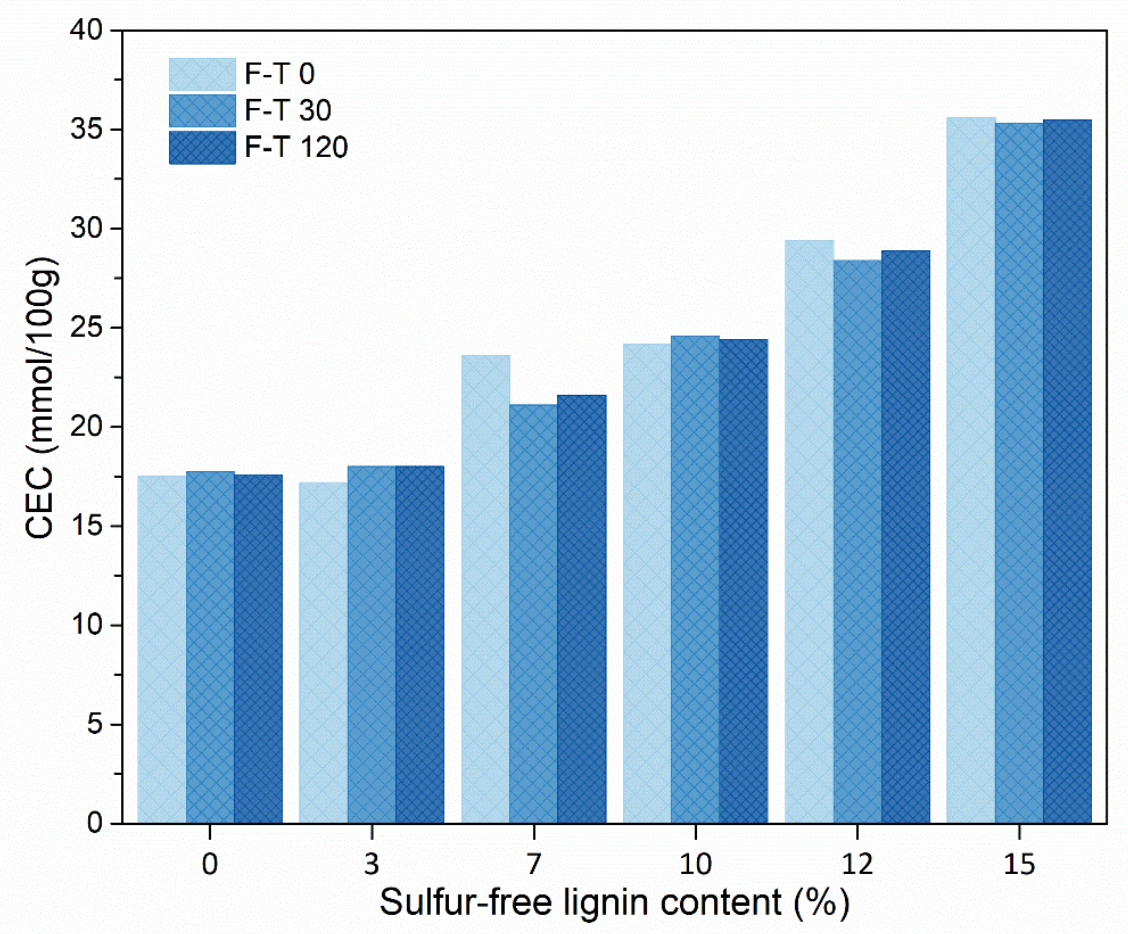

Fig. 9. Variations of cation exchange capacity for different sulfur-free lignin contents with different F-T cycles.

\subsubsection{Thermal conductivity}

The thermal conductivity of specimens decreases as the SFL content increases, reducing

320 from 1.55 to $1.19 \mathrm{~W} /(\mathrm{m} \bullet \mathrm{K})$ before any F-T cycle, as shown in Fig.10. As a natural organic

321 polymer, lignin has excellent heat insulation capacity. Its thermal conductivity ranges from

322 approximately 0.1 to $0.5 \mathrm{~W} /(\mathrm{m} \bullet \mathrm{K})$ for different plants (i.e. softwood, cotton, ramie) (Gupta et

323 al., 2003; Yapici et al., 2011), which is lower than that of soils and explains the behavior in Fig.

32410. 


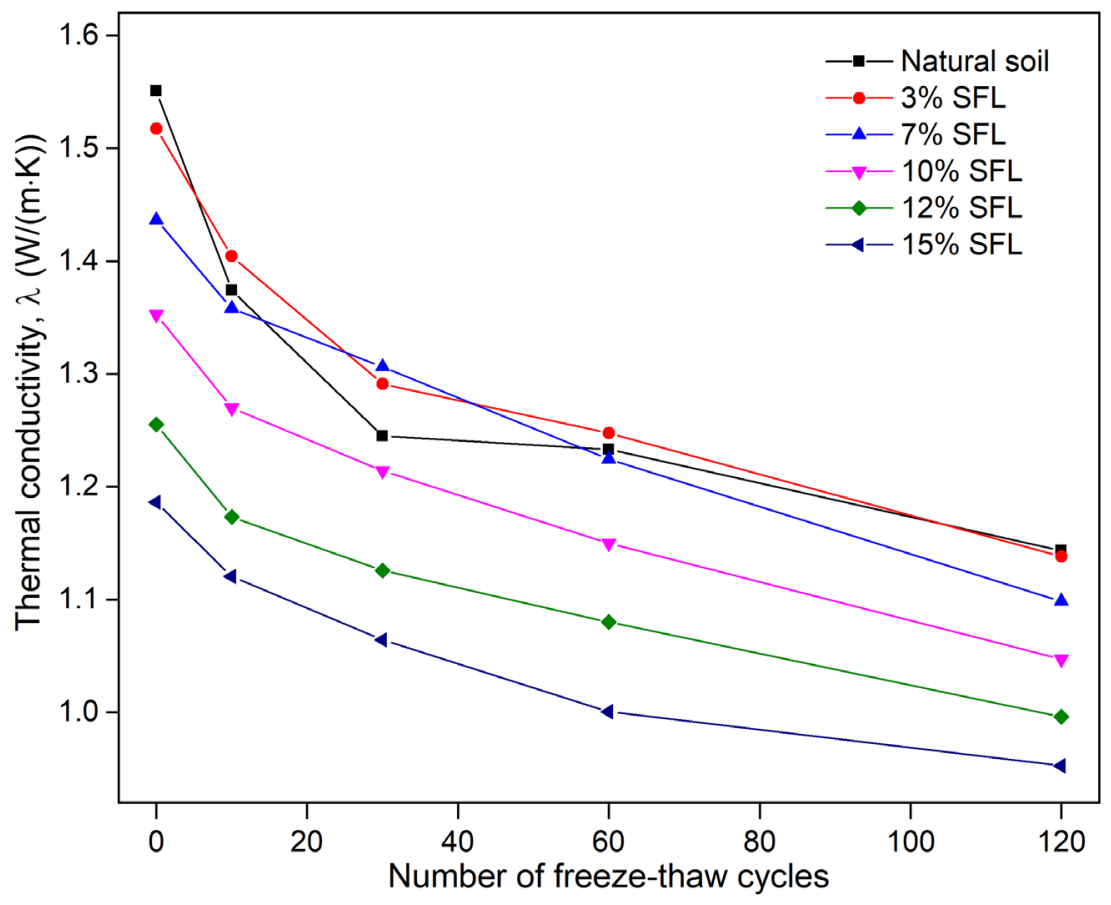

Fig. 10. Variations of thermal conductivity for different sulfur-free lignin contents with different

Fig. 10 also illustrates that the thermal conductivity of all specimens tends to decrease with increasing F-T cycles. This result is consistent with previous studies about the effects of F-T on

328 soil or concrete thermal conductivity (Pan et al., 2017; Zhang et al., 2018a). Li et al. (2019) and

329 Moghbel et al. (2018) considered that during the freezing process, the free water transitions 330 from liquid to solid ice lens, increasing the soil pore size or leading to crack formation in the 331 soil matrix. Hence, these larger pore size and gaps behave as an isolator in the heat-transfer 332 process, thereby reducing the thermal conductivity of the stabilized soil. Furthermore, Al 333 Nakshabandi and Kohnke (1965) already claimed that thermal conductivity is correlated to the 334 grain size distribution, and Abu-Hamdeh and Reeder (2000) specifically reported that thermal 335 conductivity decreases as finer particles increase. The grain-size distribution results discussed 336 earlier also support this claim. Finally, it can also be seen that the reduction is steeper for the 337 natural soil than for the SFL stabilized soil, especially during the first 30 F-T cycles, which 338 indicates that the stabilized soil has better frost resistance. 


\subsection{Mechanical test}

\subsubsection{Unconfined compressive strength test}

Fig.11(a) illustrates the Unconfined Compressive Strength (UCS) of the SFL stabilized soil undergoing different F-T cycles. It is observed that the compressive strength $\left(q_{u}\right)$ of the specimens initially increases and then reduces as the SLF content increases. The maximum $q_{u}$ was found at $10 \%$ content, reaching $1159 \mathrm{kPa}$, which it is close to the strength at $12 \% \mathrm{SFL}$ content $(1066 \mathrm{kPa})$. The UCS strength of $10 \%$ stabilized soil increases about $500 \%$ after 28 days curing compared with that of the untreated soil, which means SFL is quite efficient in improving strength. Yang et al (2018) used lignin to treat clayed sand, sandy silt with clay and sandy silt and found that the UCS increased up to 300,370 and 500\% respectively after 28 days curing. These results support the UCS performances obtained from this paper. Based on the grain size distribution results, it appears that the decrease in $q_{u}$ when the SFL content increases beyond $10 \%$ may be ascribed to excessive SFL, which prevents bonding between soil particles. This suggests that the optimum SFL content for improving and enhancing the silt clay soil in Jilin Province is between $10 \%$ and $12 \%$. It is also noteworthy that USC clearly drops during the first 10 F-T cycles for all soil samples. However, the UCS of high SFL content stabilized soil shows a considerable decrease up to $60 \mathrm{~F}-\mathrm{T}$ cycles reaching about $480 \mathrm{kPa}$. Similar trends were reported by Kravchenko et al. (2018) and Li et al. (2013), who used fibers to improve clay soils and silt soils. The F-T cycle is considered as a process of dynamic equilibrium where the formation and melting of ice gradually leads to a relative stable soil structure (Lee et al., 1995; Zhang et al., 2015b). In other words, more F-T cycles are required to reach a new balance in a stable soil structure compared to a loose soil matrix. Wang et al. (2007) thought the internal fabric of fine-grained soil usually reaches to a new dynamic balance when the soil has been exposed to $6-10$ F-T cycles. This suggests that the SFL stabilized soil has better frost resistance and the untreated soil is almost completely lost strength once it is exposed to F-T cycles. 

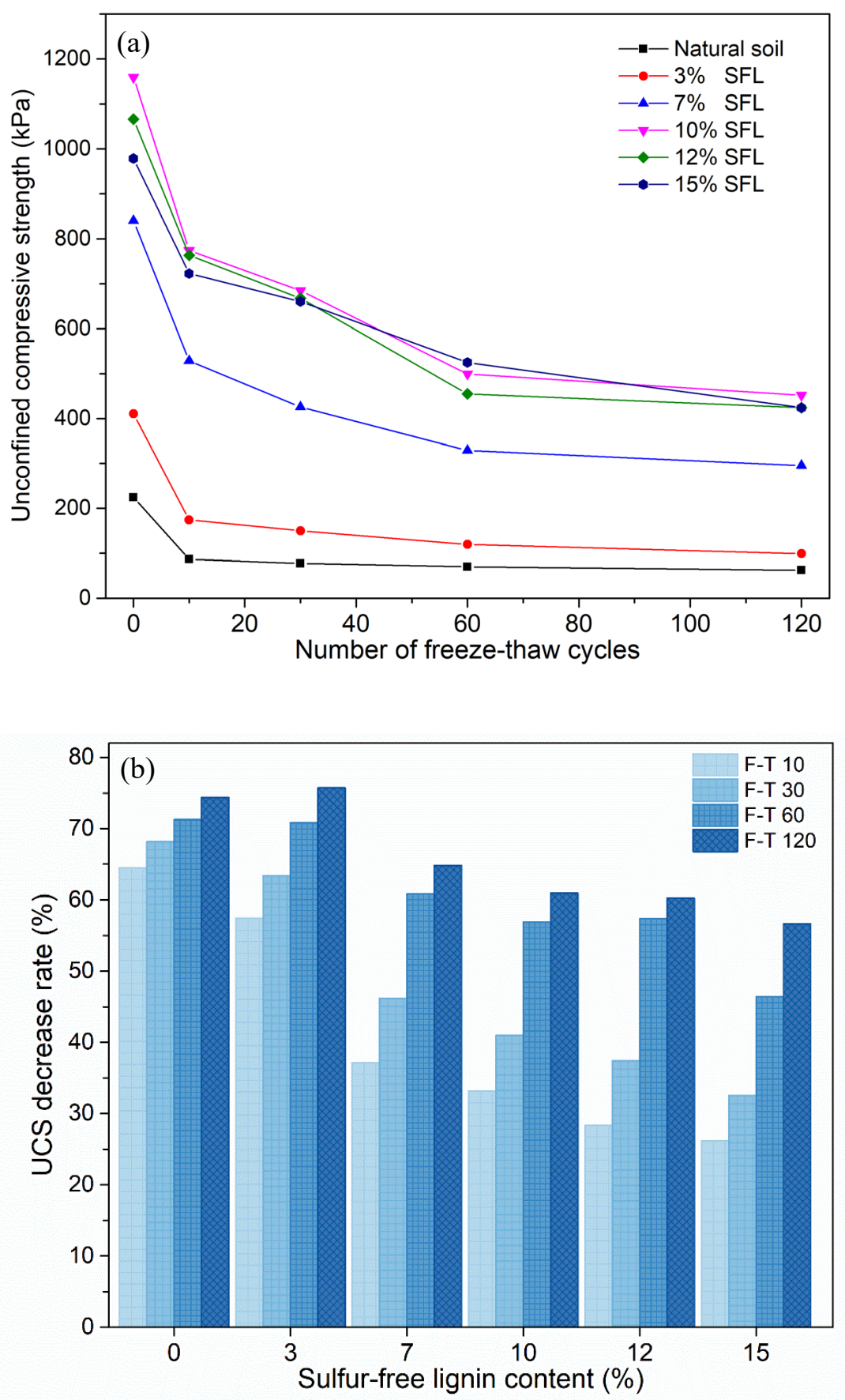

Fig. 11. (a) Variations of unconfined compressive strength for different sulfur-free lignin contents with different F-T cycles (b) Variations of unconfined compressive strength decrease rate with different F-T cycles.

In order to better analyze the frost resistance of the soil specimens, Fig.11 (b) presents the

368 variation of UCS decrease rate under different F-T cycles, which is expressed as

$$
S D R_{n}=\frac{q_{u n}-q_{u 0}}{q_{u 0}}
$$


Where $S D R_{n}$ is the UCS decrease rate of the soil specimens after $n$ F-T cycles, $q_{u n}$ is the

371 strength value after $n$ F-T cycles and $q_{u 0}$ is the strength of the specimens after 28 days curing

372 before undergoing any F-T cycles. It can be seen that the UCS decrease for the untreated soil is 373 approximately $65 \%$ during the first 10 cycles and ultimately reaches about $74 \%$. As the amount 374 of SFL increases, the performance to frost resistance is better under few F-T cycles. For instance, 375 the strength of $15 \%$ stabilized soil only decreases about $26 \%$ and $33 \%$, respectively, after 10 and 30 F-T cycles, which is a significant improvement in terms of frost resistance. The

377 difference in $S D R_{n}$ for $10 \%$ and $12 \%$ SFL stabilized soil, which is about $60 \%$ and $65 \%$, 378 respectively, is not apparent after 60 and 120 cycles. Moreover, the $15 \%$ SFL stabilized soil 379 shows the best frost resistance under high F-T cycles, with the lowest strength reduction rate of $38046 \%$ and $57 \%$ related to 60 and 120 cycles. Although less strength reduction is observed in the 381 natural soil or low SFL content stabilized soil, the absolute UCS value after reduction is overall 382 higher for high SFL contents. These results may be attributed to the relatively heavy molecular 383 mass of lignin, making it more stable, just like its supporting and strengthening function in the 384 cell wall of plants (Gandini and Belgacem, 2008). According to the above results, SFL could effectively improve the frost resistance of soils.

\subsection{Elemental and mineral composition}

\subsubsection{X-ray Diffraction analysis}

Fig.12 shows the X-Ray Diffraction (XRD) patterns of the natural soil and $15 \%$ SFL stabilized soil with no F-T cycles and 120 cycles. As lignin is an amorphous material (Han et al., 2019) and therefore it is not responsive to XRD testing, comparison of the diffraction peak patterns for the untreated soil and the SFL stabilized soil shows that no new mineral is formed by chemical reactions, as they are almost identical. This is opposite to the results from Modarres et al (2015) and Amini et al (2019), who used lime and cement to improve soil, respectively. There, new diffraction peaks for hydrated calcium silicate (CSH) and hydrated calcium aluminates $(\mathrm{CAH})$ were found in the stabilized soil. Nonetheless, there is still a noticeable difference in the peak intensity of the stabilized soil, which has a slightly decrease compared to

397 the untreated soil. Alazigha et al (2018) observed the same phenomenon when using 
$398 \equiv$ lignosulfonate to improve expansive soil and thought this may be due to the amorphous 399 properties of lignin restrictiving diffraction of mineral atomic planes. The same main minerals 400 were detected and identified in all soil specimens and include Quartz, Plagioclase, Calcite, Illite 401 and Illite/Smectite mixed layer, as indicated in Fig.12. Furthermore, no change can be observed 402 before and after 120 F-T cycles indicating that F-T cycles cannot dissolve the minerals. This is 403 consistent with results by Zhao et al. (2019). Based on XRD results, SFL does not strengthen 404 the soil through chemical reaction to generate new composition unlike lime or $\mathrm{MgO}$.

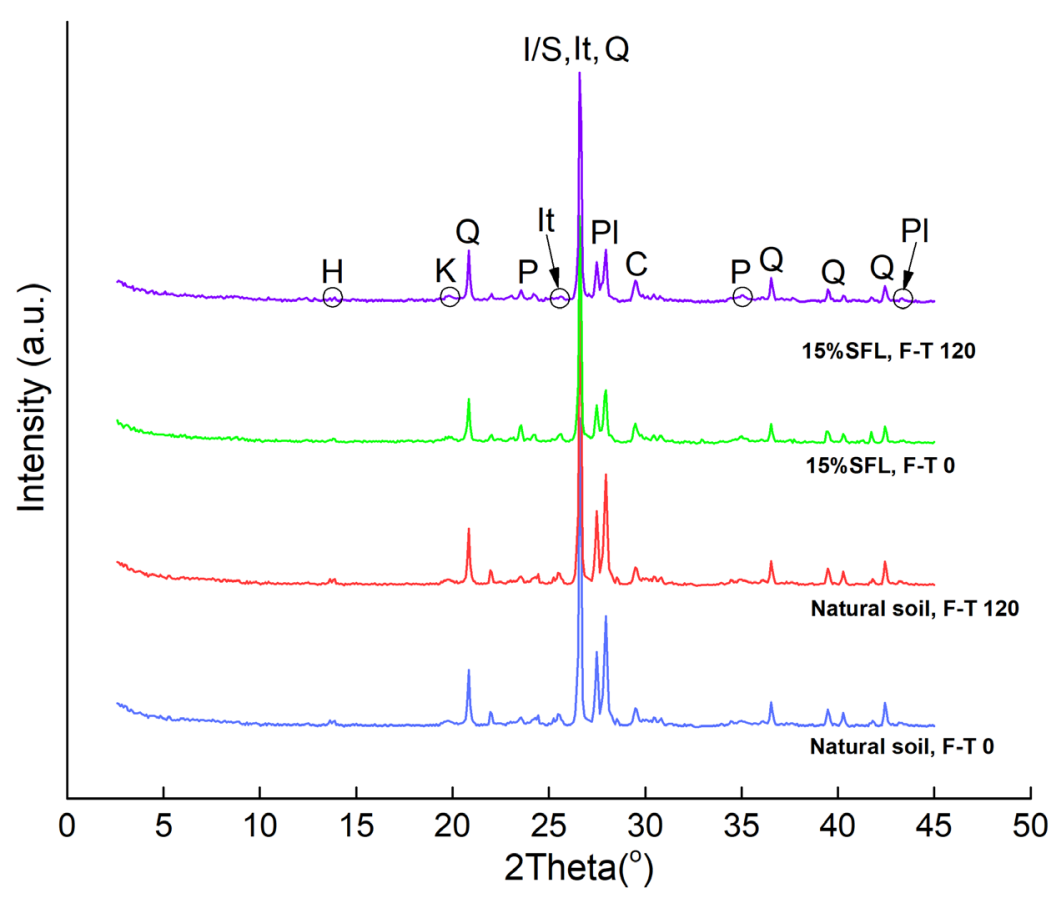

Fig. 12. XRD diffraction patterns of natural soil and $15 \%$ SFL stabilized soil under 0 F-T cycles and 120 F-T cycles (PI: plagioclase; P: potassium feldspar; C: calcite; H: hornblende; It: illite; K: kaolinite; Q: quartz; I/S: illite/ smectite mixed layer).

\subsubsection{X-ray Fluorescence analysis}

The elemental composition of the same four soil specimens were also examined through X-Ray Fluorescence tests (XRF) to confirm whether adding SFL would mix in other inorganic elemental compositions. The results are presented in Table. 3. It is clear that no heavy metal elements (such as chromium, nickel and cobalt) or sulfur element were detected, meaning that utilizing SFL- based bioethanol industrial by-product as a geotechnical material to strengthen

412 soil and meet engineering requirements would not cause environmental contamination issues. 
$413 \equiv$ After adding SFL, the amount of silicon dioxide is the element changing the most and it reduces

414 by about $10 \%$. Accordingly, loss on ignition (LOI) increases by about $12 \%$. This is due to the

415 fact that after $950^{\circ} \mathrm{C}$ ignition, lignin turns into organic carbon, leading to a significant increase

416 in the relative amount of LOI and relative reduction of other elements. At the same time, it can

417 also be found that there are no variations in the specimens under different F-T cycles, indicating

418 F-T has no effects on elemental composition, consistently with the XRD results.

Table 3

The elemental composition of $0 \%$ and $15 \%$ SFL stabilized with no and high F-T cycles

\begin{tabular}{llllllllllllll}
\multirow{2}{*}{ Sample ID } & \multicolumn{110}{c}{ Composition (\%) } \\
\cline { 2 - 13 } & $\mathrm{SiO}_{2}$ & $\mathrm{Al}_{2} \mathrm{O}_{3}$ & $\mathrm{Fe}_{2} \mathrm{O}_{3}$ & $\mathrm{FeO}$ & $\mathrm{CaO}$ & $\mathrm{MgO}$ & $\mathrm{K}_{2} \mathrm{O}$ & $\mathrm{Na}_{2} \mathrm{O}$ & $\mathrm{TiO}_{2}$ & $\mathrm{P}_{2} \mathrm{O}_{5}$ & $\mathrm{MnO}$ & LOI & Total \\
\hline 0\% SFL F-T 0 & 66.27 & 11.55 & 2.51 & 0.40 & 5.04 & 1.69 & 2.88 & 2.57 & 0.50 & 0.07 & 0.07 & 6.33 & 99.90 \\
0\% SFL F-T 120 & 68.07 & 11.23 & 2.15 & 0.43 & 4.55 & 1.58 & 2.93 & 2.62 & 0.48 & 0.07 & 0.06 & 5.73 & 99.92 \\
15\% SFL F-T 0 & 57.81 & 10.60 & 2.77 & 0.04 & 4.69 & 1.54 & 2.57 & 2.33 & 0.46 & 0.07 & 0.07 & 16.58 & 99.53 \\
15\% SFL F-T 120 & 56.60 & 10.85 & 2.94 & 0.04 & 4.95 & 1.53 & 2.54 & 2.19 & 0.46 & 0.06 & 0.07 & 17.49 & 99.74 \\
\hline
\end{tabular}

Note: LOI means value of loss on $950^{\circ} \mathrm{C}$ ignition.

\subsection{Micro-characterization test}

\subsubsection{Mercury intrusion porosimetry test}

Fig.13 (a) illustrates the variations of pore size distribution with SFL content before undergoing any F-T cycles. The total mercury intrusion volume gradually decreased from 0.159

424 to $0.142 \mathrm{~mL} / \mathrm{g}$, with SFL content increasing up to $15 \%$. Upon further analysis, it can be seen that the mercury volume of macropores $(4-40 \mu \mathrm{m})$ and mesopores $(0.4-4 \mu \mathrm{m})$ showed a

426 decreasing and increasing trend, respectively, after 3\% SFL addition. When SFL reaches 15\%, 427 the volume of both macropores and mesopores clearly reduced. This means that SFL first fills 428 the macropores and then diminishes the mesopores, resulting in lower porosity for the stabilized 429 soil. The same result was reported by Zhang et al. (2015) who tested the pore-size distribution 430 of lignosulfonate stabilized silt soil. In addition, it can also be easily observed that there is a 431 transformation in the differential pore size distribution from bimodal for the natural soil to 432 unimodal for high content SFL stabilized soils. For the natural specimen, two dominant pores 

can be observed around 0.02- $0.04 \mu \mathrm{m}$ diameters and $5-7 \mu \mathrm{m}$ diameters. For both $10 \%$ and

$43415 \%$ SFL stabilized soil, the peak in the differential pore volume relative to the smaller size 435 essentially disappears and the macropores shift to the left compared with that of the natural soil. 436 Zhang et al. (2015) also found soil that the soil pore structure of lignosulfonate stabilized silt 437 soil changed from bimodal for the natural soil and $2 \%$ content to a smooth unimodal distribution 438 for $8 \%$ and $12 \%$ specimens. Furthermore, it is worth noting that the $10 \%$ SFL stabilized soil, 439 which has dominant pore size diameter around $1-2 \mu \mathrm{m}$, shifts left more than the $15 \%$ 440 stabilized soil. This is consistent with the UCS result that the $10 \%$ SFL stabilized soil has better 441 strength performance than the $15 \%$ SFL stabilized soil due to denser structure.

442 Fig.13 (b) shows the pore size distribution of the natural soil and 15\% stabilized soil after $443120 \mathrm{~F}-\mathrm{T}$ cycles. The F-T process increases distinctly the cumulative intrusion of mercury in the 444 natural soil from 0.159 to $0.192 \mathrm{~mL} / \mathrm{g}$. However, the variation is about half $(0.012 \mathrm{~mL} / \mathrm{g})$ for 445 the $15 \%$ SFL stabilized soil. Moreover, the dominant macropore size of the natural soil shows 446 an evident shift to the right from 6 to $9 \mu \mathrm{m}$, while there is negligible change in the curve for 447 the $15 \%$ SFL specimen. The reason for increasing porosity and dominant pore size is mainly 448 because the free water in the soil pores expands about nine-percent during the freezing process 449 leading to permanent changes in the pore-size distribution characteristics (Konrad, 1989). At 450 the same time, these results are consistent with the thermal conductivity and UCS tests and 451 prove that SFL could effectively improve the frost resistance of the stabilized soil. 

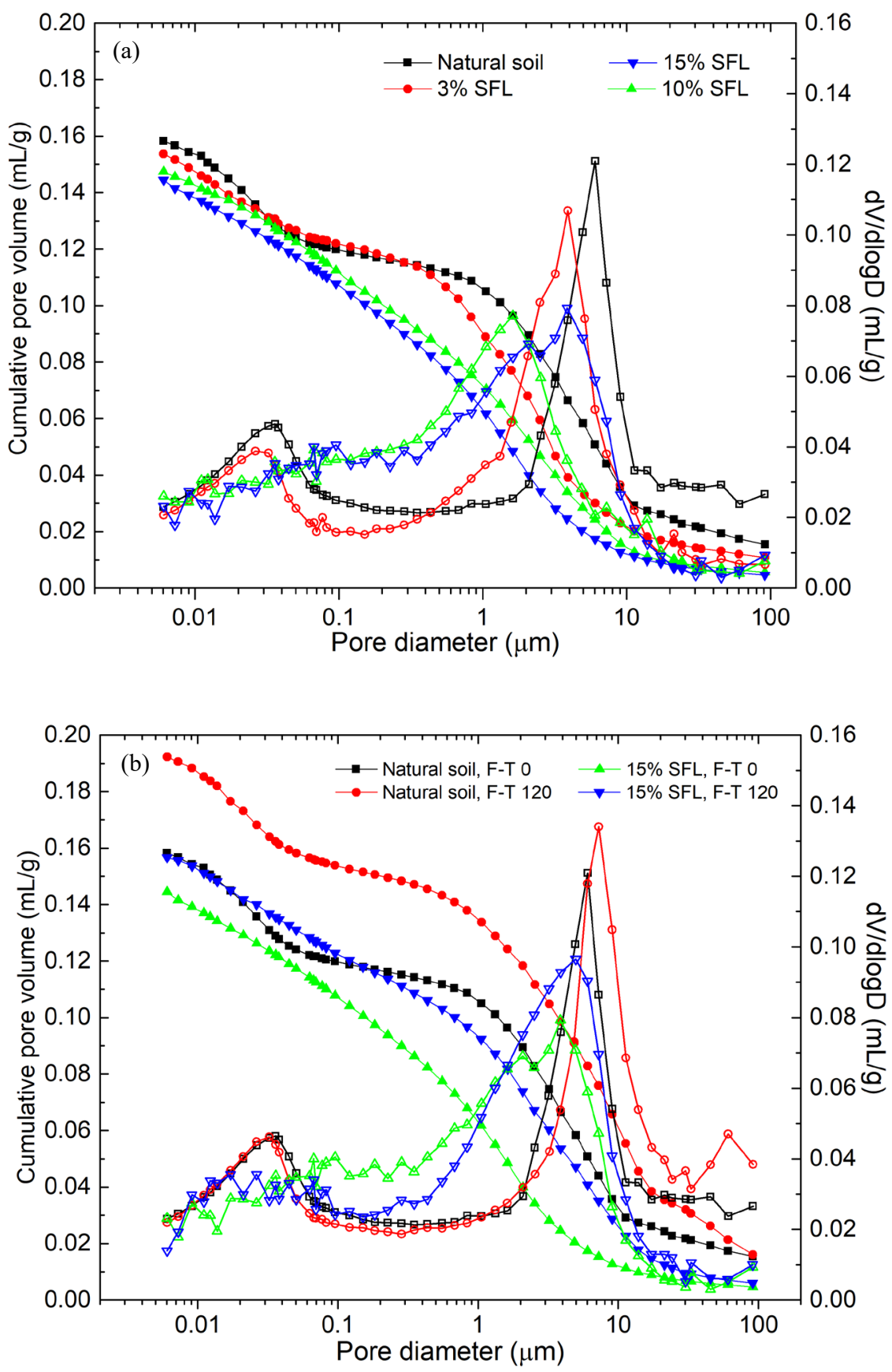

Fig. 13. (a) Mercury intrusion porosimetry results for different SFL contents after 28 days curing without F-T cycles; (b) Mercury intrusion porosimetry results forf natural soil and $15 \%$ SFL stabilized soil with no and 120 F-T cycles.

\subsubsection{Scanning electron microscopy (SEM)}


$456 \equiv$ see that the soil particles of the natural soil are connected with each other mainly by point 457 contact, without any cementing, while the soil particles are coated and bonded by adhesive 458 material formed after mixing SFL. Moreover, the natural soil shows a looser structure with 459 more pores in contrast with a denser and hence more stable structure for the stabilized soil, due 460 to more aggregated soil particles. Fig.14 (c) also shows that small soil particles agglomerate 461 together to form large particles. Through magnifying a detail (Fig. 14(d)), it can be seen that 462 the individual soil particles are coated with natural polymer that binds the particles together. 463 Combining the above to XRD, XRF, and CEC results, it appears that the SFL stabilizes the soil 464 by physically bonding the soil particles together. The bonding could be ascribed to electrostatic 465 attraction between sulfur-free lignin and soil minerals, as proposed by Tingle et al. (2007) and 466 Vinod et al. (2010). Fig.14 (c) and Fig.14 (d) show that F-T has undesirable effects on the 467 solidified soil matrix, accounting for the looser soil structure. Furthermore, several 468 microfractures are generated on the surface of natural soil particles, which indicates the soil 469 particles started to break into smaller ones (Fig.14 (e)). Some researchers (Poltev, 1968; Zhang 470 et al. 2016) suggested that the phase change of free water (from liquid to solid phase) generates 471 micro-cracks on the surface of soil particles by temperature tension and then these micro-cracks 472 are filled by water film and sustainably develop into macro-cracks (width about $10 \mu \mathrm{m}$ ) with 473 increasing number of F-T cycles. The cracks, which the 474 forces during the F-T process, were found both in the fine soil matrix and the coarse particles 475 of the stabilized soils. As a result, these macro-cracks crushed the coarse particles and resulted 476 in a scattered structure in the SFL treated soil as shown in Fig. 14 (f). The macro-cracks induced 477 by F-T cycles at aggregates scale were also observed by Olgun (2013) and Liu et al. (2019). 

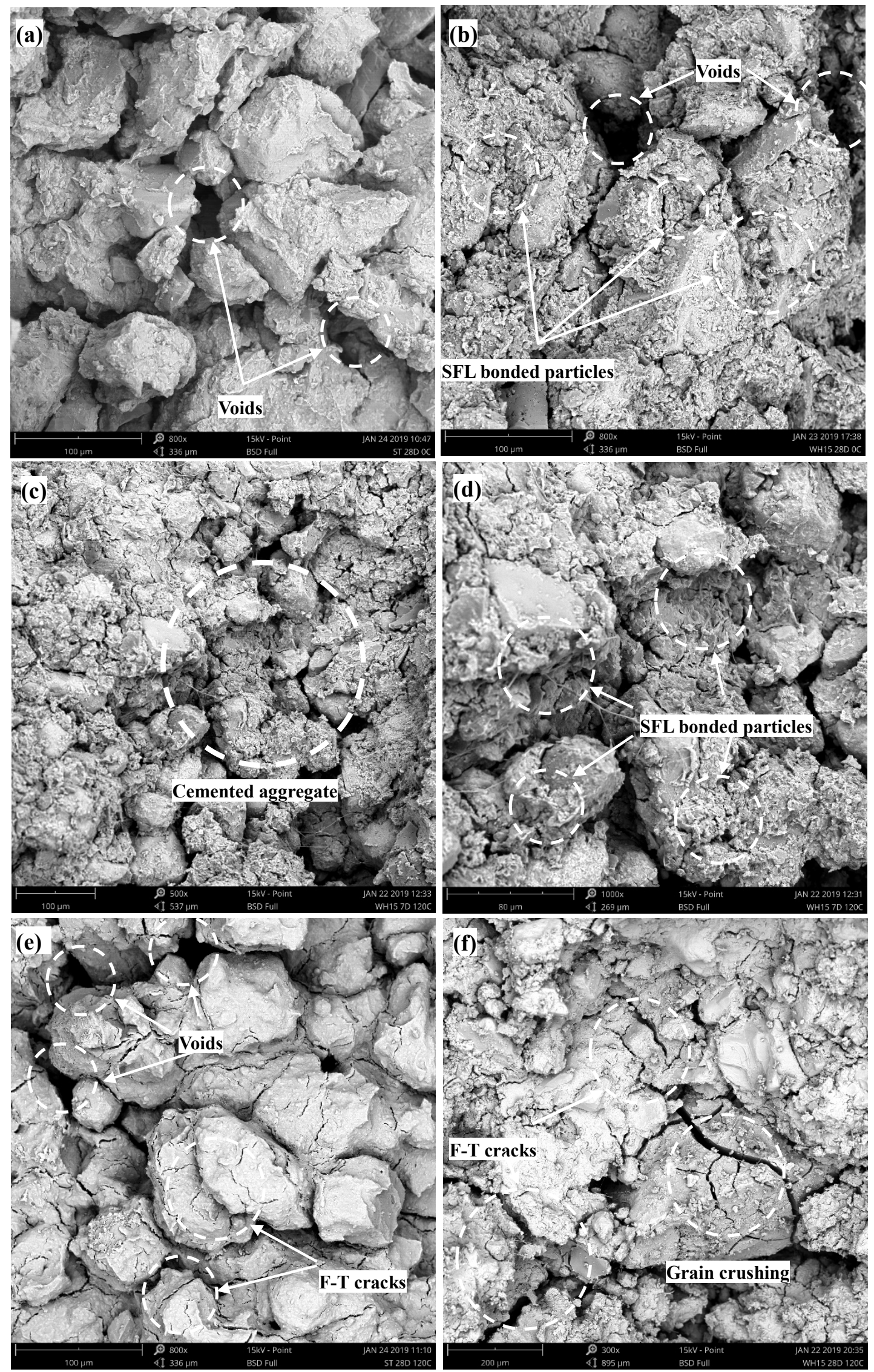

Fig. 14 Scanning electron microscopy images of the natural soil and the SFL stabilized soil without and with 120 F-T cycles: (a) natural soil and no F-T cycles; (b) 15\% SFL stabilized soil after 28 days curing and no F-T cycles; (c) $15 \%$ SFL stabilized soil after 7 days curing and 120 F-T cycles ( $\times 500$ ); (d) $15 \%$ SFL stabilized soil after 7 days curing and 120 F-T cycles (×1000); (e) natural soil and 120 F-T cycles; (f) $15 \%$ SFL stabilized soil after 28 days 
This paper shows the use of Sulfur-Free Lignin (SFL) to stabilize soil for earth works. The geotechnical properties of stabilized soil-SFL mixtures were comprehensively investigated from a physicochemical, mechanical, elemental and mineral composition point of view, interpreting the results from a micro-mechanical perspective. A considerable improvement in uniaxial compression strength was observed, which increase with SFL content up to $12 \%$. The physical properties also changed, but not the chemical ones. Therefore, the stabilization mechanism consists in physical binding unlike for traditional soil stabilizers. Moreover, the stabilization and damage mechanisms under climatic factors (Freeze-Thaw cycling) were also investigated and it was found that SFL addition improved frost resistance. In particular, according to the results:

- The consistency limits increased slightly when adding SFL, while the coarse soil particles (sand and silt groups) exhibited a significant increase.

- The use of $\mathrm{NaOH}$ in the production process of bioethanol leads to a considerable CEC increase in the SFL stabilized soil. However, the $\mathrm{pH}$ was unchanged regardless of the SFL\% added.

- After curing 28 days, the unconfined compressive strength increased about 5 times (230 to $1158 \mathrm{kPa}$ ) for the $10 \% \mathrm{SFL}$ stabilized soil, which is around to the optimum SFL dosage.

- With increasing SFL content the porosity fabric changed from bimodal to unimodal and the total pore volume decreased, but no new mineral was formed nor change in elemental composition. The stabilization mechanism therefore consists in physical binding such as coating finer soil particles, bonding isolated particles and filling intra-aggregate pores unlike traditional soil stabilizers.

- The frost resistance showed a considerable improvement with increasing SFL content. Even if UCS reduced with F-T cycles, due to physical damage (such as crushing of coarse particles and cracking of the fine soil matrix), it remained 7 times higher for the SFL treated soil even after 120 cycles. Furthermore, adding SFL increases the thermal insulating properties of the treated soil improving frost resistance.

Based on these experimental results, SFL shows great potential as a novel stabilizer to 
improve the engineering behavior of soil and offers an alternative to traditional chemical agents, particularly because it does not risk inducing soil $\mathrm{pH}$ contamination. However, SFL should be

511 used cautiously to treat dispersive soils due to increased CEC. Further work should address 512 climate factors under dry-wet cycles and the dynamic behavior should be evaluated in relation to the use of SFL-stabilized soils as road substrates are subjected to traffic loading.

\section{Acknowledgements}

The authors are grateful for the financial support for the study presented in this paper from the Key Program of International (Regional) Cooperation and Exchange of National Natural Science Foundation (Grant No. 41820104001), State Key Program of the National Natural Science Foundation of China (Grant No. 41430642) and the Special Fund for Major Scientific Instruments of the National Natural Science Foundation of China (Grant No. 41627801). The authors also would like to appreciate Yifan Wang, Junyuan Liu, Yating Chen, Mengxia Han,

521 Jiejie Shen, Feifan Gu and Shaotao Xu from College of Engineering Construction, Jilin University for their indispensable assistance in the experimental process. In addition, the first author Yaowu Liu would also like to thank the support form State Scholarship Fund of China Scholarship Council (CSC NO. 201806170226).

\section{Reference}

Abe, A., Dusek, K., Kobayashi, S., 2010. Biopolymers: lignin, proteins, bioactive nanocomposites. Springer Science \& Business Media. Abu-Hamdeh, N.H., Reeder, R.C., 2000. Soil thermal conductivity effects of density, moisture, salt concentration, and organic matter. Soil science society of America Journal 64, 1285-1290. Ajanovic, A., Haas, R., 2010. Economic challenges for the future relevance of biofuels in transport in EU countries. Energy 35, 3340-3348. Al-Homoud, A.S., Khoury, H., Al-Omari, Y.A., 1996. Mineralogical and engineering properties of problematic expansive clayey beds causing landslides. Bulletin of the International Association of Engineering Geology - Bulletin de l'Association Internationale de Géologie de 535 l'Ingénieur 54, 13-31. Al Nakshabandi, G., Kohnke, H., 1965. Thermal conductivity and diffusivity of soils as related to moisture tension and other physical properties. Agricultural Meteorology 2, 271-279. Alazigha, D.P., Indraratna, B., Vinod, J.S., Heitor, A., 2018. Mechanisms of stabilization of expansive soil with lignosulfonate admixture. Transportation Geotechnics 14, 81-92. Alsina, O.L., De Carvalho, L., Ramos Filho, F.G.d., d'Almeida, J.R., 2005. Thermal properties 
of hybrid lignocellulosic fabric-reinforced polyester matrix composites. Polymer Testing 24, 81-85.

ASTM, 2002. ASTM D4219-02, 2002. Test Method ofr Unconfined Compressive Sterength Index of Chemical-Grouted Soils.

ASTM, 2007. ASTM D4972-01, 2007. Standard Test Methods for $\mathrm{pH}$ of Soils.

ASTM, 2010. ASTM D4318-10, 2010. Standard Test Methods for Liquid Limit, Plastic Limit, and Plasticity Index of Soils.

Bettiga, M., Bengtsson, O., Hahn-Hägerdal, B., Gorwa-Grauslund, M.F., 2009. Arabinose and xylose fermentation by recombinant Saccharomyces cerevisiae expressing a fungal pentose utilization pathway. Microbial Cell Factories 8, 40.

Bothast, R., Schlicher, M., 2005. Biotechnological processes for conversion of corn into ethanol. Applied microbiology and biotechnology 67, 19-25.

Ceylan, H., Kim, S., Gopalakrishnan, K., 2012. Sustainable utilization of bio-fuel co-product in roadbed stabilization, Sustainable Bioenergy and Bioproducts. Springer, pp. 117-129.

Chen, H., Wang, Q., 2006. The behaviour of organic matter in the process of soft soil stabilization using cement. Bulletin of Engineering Geology and the Environment 65, 445-448. Chen, Q., Indraratna, B., Carter, J., Rujikiatkamjorn, C., 2014. A theoretical and experimental study on the behaviour of lignosulfonate-treated sandy silt. Computers and Geotechnics 61, 316-327.

Cheng, Z., Xu, Z., Zhang, L., Wang, X., 2014. Thermophysical Properties of Lignocellulose: A Cell-Scale Study Down to 41K. PloS one 9, e114821.

China, M.o.C.o.t.P.R.o., 1999. Standard for Soil Test Methods (GB/T 50123-1999). China Planning Press, Beijing.

China, N.E.A.o., 2010a. Annalysis method for clay minerals and ordinary non-clay minerals in sedimentary rocks by the X-ray diffraction, SY/T 5163-2010.

China, T.C.P.s.G.o.t.P.s.R.o., 2010b. Methods for chemical analysis of silicate rocks. Standards Press of China

Chio, C., Sain, M., Qin, W., 2019. Lignin utilization: A review of lignin depolymerization from various aspects. Renewable and Sustainable Energy Reviews 107, 232-249.

Council, N.R., 2006. Geological and Geotechnical Engineering in the New Millennium: Opportunities for Research and Technological Innovation. The National Academies Press, Washington, DC.

Dagesse, D.F., 2015. Cyclic freezing and thawing effects on Atterberg limits of clay soils, Proceedings of the 68th Canadian Geotechnical Conference and 7th Canadian Permafrost Conference, pp. 20-23.

Delage, P., 1984. Influence De La Lyophilisation Sur La Structure D'une Argile Sensible Du Quebec. Clay Minerals 19, 151-160.

Di Donato, P., Finore, I., Poli, A., Nicolaus, B., Lama, L., 2019. The production of second generation bioethanol: The biotechnology potential of thermophilic bacteria. Journal of Cleaner Production 233, 1410-1417.

Fang, H.-Y., 2013. Foundation engineering handbook. Springer Science \& Business Media.

Gandini, A., Belgacem, M.N., 2008. Lignins as components of macromolecular materials, Monomers, polymers and composites from renewable resources. Elsevier, pp. 243-271.

Ghadir, P., Ranjbar, N., 2018. Clayey soil stabilization using geopolymer and Portland cement. 
Construction and Building Materials 188, 361-371.

Gopalakrishnan, K., Ceylan, H., Kim, S., 2013. Renewable biomass-derived lignin in transportation infrastructure strengthening applications.

Gupta, M., Yang, J., Roy, C., 2003. Specific heat and thermal conductivity of softwood bark

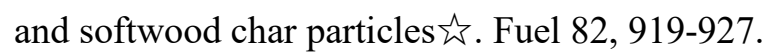

Hamelinck, C.N., Hooijdonk, G.v., Faaij, A.P.C., 2005. Ethanol from lignocellulosic biomass: techno-economic performance in short-, middle- and long-term. Biomass and Bioenergy 28, 384-410.

Han, T., Sophonrat, N., Tagami, A., Sevastyanova, O., Mellin, P., Yang, W., 2019. Characterization of lignin at pre-pyrolysis temperature to investigate its melting problem. Fuel 235, 1061-1069.

Higgins, D., 2007. Briefing: GGBS and sustainability. Thomas Telford Ltd.

Holtz, R.D., Kovacs, W.D., Sheahan, T.C., 1981. An introduction to geotechnical engineering. Prentice-Hall Englewood Cliffs, NJ.

Indraratna, B., Muttuvel, T., Khabbaz, H., 2008. Investigating Erosional Behaviour of Chemically Stabilised Erodible Soils.

Ismaiel, H.A.H., 2006. Treatment and improvement of the geotechnical properties of different soft fine-grained soils using chemical stabilization. Shaker.

Jefferis, S.A., 2008. Moving Towards Sustainability in Geotechnical Engineering, GeoCongress 2008, pp. 844-851.

Jiangying, L., Dimin, X., Xiong, L., Hills, C., Carey, P., Gardner, K., 2008. Comparison of properties of traditional and accelerated carbonated solidified/stabilized contaminated soils. Journal of Environmental Sciences 20, 593-598.

Konrad, J.-M., 1989. Physical processes during freeze-thaw cycles in clayey silts. Cold Regions Science and Technology 16, 291-303.

Kravchenko, E., Liu, J., Niu, W., Zhang, S., 2018. Performance of clay soil reinforced with fibers subjected to freeze-thaw cycles. Cold Regions Science and Technology 153, 18-24.

Lamond, J.F., Pielert, J.H., 2006. Significance of tests and properties of concrete and concretemaking materials. Astm West Conshohocken, PA.

Lee, J.K., Shang, J.Q., 2014. Evolution of thermal and mechanical properties of mine tailings and fly ash mixtures during curing period. Canadian Geotechnical Journal 51, 570-582.

Lemaire, K., Deneele, D., Bonnet, S., Legret, M., 2013. Effects of lime and cement treatment on the physicochemical, microstructural and mechanical characteristics of a plastic silt. Engineering Geology 166, 255-261.

Li, C., Zhao, X., Wang, A., Huber, G.W., Zhang, T., 2015. Catalytic Transformation of Lignin for the Production of Chemicals and Fuels. Chemical Reviews 115, 11559-11624.

Li, R., Zhao, L., Wu, T., Wang, Q.X., Ding, Y., Yao, J., Wu, X., Hu, G., Xiao, Y., Du, Y., Zhu, X., Qin, Y., Shuhua, Y., Bai, R., Erji, D., Liu, G., Zou, D., Yongping, Q., Shi, J., 2019. Soil thermal conductivity and its influencing factors at the Tanggula permafrost region on the Qinghai-Tibet Plateau.

Liitia, T., Rovio, S., Talja, R., Tamminen, T., Rencoret, J., Gutierrez, A., del Rio, J., Saake, B., Schwarz, K., Vilababaro, C., 2014. Structural characteristics of industrial lignins in respect to their valorization.

Lin, S.Y., Dence, C.W., 2012. Methods in lignin chemistry. Springer Science \& Business Media. 
Lisperguer, J., Perez, P., Urizar, S., 2009. Structure and thermal properties of lignins: characterization by infrared spectroscopy and differential scanning calorimetry. Journal of the Chilean Chemical Society 54, 460-463.

Liu, Y., Wang, Q., Liu, S., ShangGuan, Y., Fu, H., Ma, B., Chen, H., Yuan, X., 2019. Experimental investigation of the geotechnical properties and microstructure of lime-stabilized saline soils under freeze-thaw cycling. Cold Regions Science and Technology.

Martone, P.T., Estevez, J.M., Lu, F., Ruel, K., Denny, M.W., Somerville, C., Ralph, J., 2009. Discovery of lignin in seaweed reveals convergent evolution of cell-wall architecture. Current biology 19, 169-175.

Moghbel, F., Fall, M., 2018. Thermal Properties of Compost Biocover Subjected to FreezeThaw Cycles. Journal of Cold Regions Engineering 32, 04018008.

Mueller, S.A., Anderson, J.E., Wallington, T.J., 2011. Impact of biofuel production and other supply and demand factors on food price increases in 2008. Biomass and Bioenergy 35, 1623 1632.

Nechita, P., Ionescu, Ş.M., 2018. Investigation on the thermal insulation properties of lightweight biocomposites based on lignocellulosic residues and natural polymers. Journal of Thermoplastic Composite Materials 31, 1497-1509.

Pérez, I.P., Rodríguez Pasandín, A.M., Pais, J.C., Alves Pereira, P.A., 2019. Use of lignin biopolymer from industrial waste as bitumen extender for asphalt mixtures. Journal of Cleaner Production 220, 87-98.

Pan, P., Wu, S., Hu, X., Wang, P., Liu, Q., 2017. Effect of freezing-thawing and ageing on thermal characteristics and mechanical properties of conductive asphalt concrete. Construction and Building Materials 140, 239-247.

Peck, R.B., Hanson, W.E., Thornburn, T.H., 1974. Foundation engineering. Wiley New York. Peralta, J., Raouf, M.A., Tang, S., Williams, R.C., 2012. Bio-renewable asphalt modifiers and asphalt substitutes, Sustainable bioenergy and bioproducts. Springer, pp. 89-115.

Pourhashem, G., Adler, P.R., Spatari, S., 2016. Time effects of climate change mitigation strategies for second generation biofuels and co-products with temporary carbon storage. Journal of Cleaner Production 112, 2642-2653.

$\mathrm{Qu}, \mathrm{Y}$, 2007. Industrialization of cellulosic ethanol.

Reddy, K.R., Kumar, G., 2019. Role of Geochemistry in Sustainable Geotechnics, Environmental Geotechnology. Springer, pp. 1-15.

Russo, G., Vecchio, S.D., Mascolo, G., 2007. Microstructure of a Lime Stabilised Compacted Silt. Springer Berlin Heidelberg.

Santoni, R.L., Tingle, J.S., Webster, S.L., 2002. Stabilization of silty sand with nontraditional additives. Transportation research record 1787, 61-70.

Sharma, N.K., Swain, S.K., Sahoo, U.C., 2012. Stabilization of a Clayey Soil with Fly Ash and Lime: A Micro Level Investigation. Geotechnical and Geological Engineering 30, 1197-1205. Sierra, R., Smith, A., Granda, C., Holtzapple, M.T., 2008. Producing fuels and chemicals from lignocellulosic biomass. Chemical Engineering Progress 104, S10-S18.

Sreekrishnavilasam, A., Rahardja, S., Kmetz, R., Santagata, M., 2007. Soil treatment using fresh and landfilled cement kiln dust. Construction and Building Materials 21, 318-327.

Stewart, D., 2008. Lignin as a base material for materials applications: Chemistry, application and economics. Industrial crops and products 27, 202-207. 
Su, Y., Zhang, P., Su, Y., 2015. An overview of biofuels policies and industrialization in the major biofuel producing countries. Renewable and Sustainable Energy Reviews 50, 991-1003. Surdahl, R.W., Woll, J.H., Marquez, H.R., 2007. Stabilization and dust control at the Buenos Aires national wildlife refuge, Arizona. Transportation research record 1989, 312-321.

Suslick, K.S., 1998. Kirk-Othmer encyclopedia of chemical technology. J. Wiley \& Sons: New York 26, 517-541.

Ta'negonbadi, B., Noorzad, R., 2017. Stabilization of clayey soil using lignosulfonate. Transportation Geotechnics 12, 45-55.

Takara, D., Khanal, S.K., 2012. Biomass Pretreatment for Biofuel Production, in: Gopalakrishnan, K., van Leeuwen, J., Brown, R.C. (Eds.), Sustainable Bioenergy and Bioproducts: Value Added Engineering Applications. Springer London, London, pp. 59-70.

Tang, D., 1998. Engineering Rock and Soil, Second Edition ed. Geological Publishing House, Beijing.

Thives, L.P., Ghisi, E., 2017. Asphalt mixtures emission and energy consumption: A review. Renewable and Sustainable Energy Reviews 72, 473-484.

Tingle, J.S., Newman, J.K., Larson, S.L., Weiss, C.A., Rushing, J.F., 2007. Stabilization mechanisms of nontraditional additives. Transportation research record 1989, 59-67.

Tingle, J.S., Santoni, R.L., 2003. Stabilization of clay soils with nontraditional additives. Transportation Research Record 1819, 72-84.

van Dam, J.E., de Klerk-Engels, B., Struik, P.C., Rabbinge, R., 2005. Securing renewable resource supplies for changing market demands in a bio-based economy. Industrial crops and products 21, 129-144.

Vinod, J.S., Indraratna, B., Al Mahamud, M.A., 2010. Stabilisation of an erodible soil using a chemical admixture.

Wang, D., Xiao, J., Gao, X., 2019. Strength gain and microstructure of carbonated reactive MgO-fly ash solidified sludge from East Lake, China. Engineering Geology 251, 37-47.

Wang, Y., Cheng, M.-H., 2018. Greenhouse gas emissions embedded in US-China fuel ethanol trade: A comparative well-to-wheel estimate. Journal of cleaner production 183, 653-661.

Wang, Z., 1993. Chinese Saline Soil. Science Publication, Beijing.

Washburn, E.W., 1921. Note on a Method of Determining the Distribution of Pore Sizes in a Porous Material. Cambridge University Press.

Xi, F., Davis, S.J., Ciais, P., Crawford-Brown, D., Guan, D., Pade, C., Shi, T., Syddall, M., Lv, J., Ji, L., 2016. Substantial global carbon uptake by cement carbonation. Nature Geoscience 9, 880.

Yang, J., Wei, L., 2012. Collapse of loose sand with the addition of fines: the role of particle shape. Géotechnique.

Yano, S., Murakami, K., Sawayama, S., Imou, K., Yokoyama, S., 2009. Ethanol production potential from oil palm empty fruit bunches in Southeast Asian countries considering xylose utilization. Journal of the Japan Institute of Energy 88, 923-926.

Yapici, F.I., Ozcifci, A., Esen, R., Kurt, S., 2011. The effect of grain angle and species on thermal conductivity of some selected wood species. BioResources 6, 2757-2762.

Yun, Z., Wei, M., Hui, B., 2015. Impact of freezing and thawing cycles on structure of soils and its mechanism analysis by laboratory testing. Rock and Soil Mechanics 36, 1282-1287.

Zeevaert, L., 1973. Foundation engineering for difficult subsoil conditions. Van Nostrand 
Reinhold New York.

718 Zeng, Z., Kong, L., Wang, M., Sayem, H.M., 2018. Assessment of engineering behaviour of an 719 intensely weathered swelling mudstone under full range of seasonal variation and the 720 relationships among measured parameters. Canadian Geotechnical Journal 55, 1837-1849.

721 Zhan, J., Wang, Q., Zhang, W., Shangguan, Y., Song, S., Chen, J., 2019. Soil-engineering 722 properties and failure mechanisms of shallow landslides in soft-rock materials. CATENA 181, 723104093.

724 Zhang, M., Lu, J., Lai, Y., Zhang, X., 2018a. Variation of the thermal conductivity of a silty clay during a freezing-thawing process. International Journal of Heat and Mass Transfer 124, 726 1059-1067.

727 Zhang, T., 2015. Study on Technology and Engineering Application of Silt solidifed by Lignin, School of Transportaion. Southeast University, pp. 95-97.

729 Zhang, T., Cai, G., Liu, S., 2017. Application of lignin-based by-product stabilized silty soil in 730 highway subgrade: A field investigation. Journal of cleaner production 142, 4243-4257.

731 Zhang, T., Cai, G., Liu, S., 2018b. Assessment of mechanical properties in recycled lignin732 stabilized silty soil as base fill material. Journal of cleaner production 172, 1788-1799. Zhang, T., Cai, G., Liu, S., 2018c. Reclaimed Lignin-Stabilized Silty Soil: Undrained Shear Strength, Atterberg Limits, and Microstructure Characteristics. Journal of Materials in Civil 735 Engineering 30, 04018277.

736 Zhang, T., Liu, S., Cai, G., Puppala, A.J., 2015. Experimental investigation of thermal and 737 mechanical properties of lignin treated silt. Engineering geology 196, 1-11.

738 Zhao, M., Zhang, G., Htet, K.W., Kwon, M., Liu, C., Xu, Y., Tao, M., 2019. Freeze-thaw 739 durability of red mud slurry-class F fly ash-based geopolymer: Effect of curing conditions. 740 Construction and Building Materials 215, 381-390. 